\title{
Environmental drivers of the fine-scale distribution of a gelatinous zooplankton community across a mesoscale front
}

\author{
Jessica Y. Luo ${ }^{1, *}$, Benjamin Grassian ${ }^{1}$, Dorothy Tang ${ }^{1}$, Jean-Olivier Irisson ${ }^{2}$, \\ Adam T. Greer ${ }^{1,3}$, Cedric M. Guigand ${ }^{1}$, Sam McClatchie ${ }^{4}$, Robert K. Cowen ${ }^{1,5}$ \\ ${ }^{1}$ Marine Biology and Fisheries, Rosenstiel School of Marine and Atmospheric Sciences, University of Miami, \\ 4600 Rickenbacker Causeway, Miami, Florida 33149, USA \\ ${ }^{2}$ Ocean Observatory of Villefranche-sur-Mer, University of Pierre and Marie Curie, 181 Chemin du Lazaret, \\ 06230 Villefranche-sur-Mer, France \\ ${ }^{3}$ College of Engineering, University of Georgia, 200 D.W. Brooks Dr., Athens, Giorgia 30602, USA \\ ${ }^{4}$ Southwest Fisheries Science Center, NOAA Fisheries, 8901 La Jolla Shores Drive, La Jolla, California 92037, USA \\ ${ }^{5}$ Hatfield Marine Science Center, Oregon State University, 2030 SE Marine Science Drive, Newport, Oregon 97365, USA
}

\begin{abstract}
Mesoscale fronts occur frequently in many coastal areas and often are sites of elevated productivity; however, knowledge of the fine-scale distribution of zooplankton at these fronts is lacking, particularly within the mid-trophic levels. Furthermore, small $(<13 \mathrm{~cm})$ gelatinous zooplankton are ubiquitous, but are under-studied, and their abundances underestimated due to inadequate sampling technology. Using the In Situ Ichthyoplankton Imaging System (ISIIS), we describe the fine-scale distribution of small gelatinous zooplankton at a sharp salinitydriven front in the Southern California Bight. Between 15 and 17 October 2010, over 129000 hydromedusae, ctenophores, and siphonophores within 44 taxa, and nearly 650000 pelagic tunicates were imaged in $5450 \mathrm{~m}^{3}$ of water. Organisms were separated into 4 major assemblages which were largely associated with depth-related factors. Species distribution modeling using boosted regression trees revealed that hydromedusae and tunicates were primarily associated with temperature and depth, siphonophores with dissolved oxygen (DO) and chlorophyll a fluorescence, and ctenophores with DO. The front was the least influential out of all environmental variables modeled. Additionally, except for 6 taxa, all other taxa were not aggregated at the front. Results provide new insights into the biophysical drivers of gelatinous zooplankton distributions and the varying influence of mesoscale fronts in structuring zooplankton communities.
\end{abstract}

KEY WORDS: Gelatinous zooplankton · Jellyfish · Fronts · Community dynamics · Aggregations · Environmental drivers $\cdot$ Imaging systems $\cdot$ Southern California Bight

Resale or republication not permitted without written consent of the publisher

\section{INTRODUCTION}

Gelatinous zooplankton, which include medusae, ctenophores, siphonophores, and pelagic tunicates, are pervasive consumers in marine environments (Purcell \& Arai 2001). Many have life histories that result in dramatic boom and bust cycles that have the potential to disrupt fisheries, human activities, and nutrient cycling (Pitt et al. 2009, Purcell 2012). Physical factors that typically influence the patchy accumulation of plankton (e.g. fronts, eddies, etc.) also drive gelatinous zooplankton aggregations (Graham et al. 2001), which may result in the rapid predation of plankton prey. To date, most attention has been paid to the large, conspicuous scyphomedusae despite the ubiquity and abundance of the smaller gelat- 
inous zooplankton (mms to $\mathrm{cms}$ in size) in coastal areas (e.g. Pagès \& Gili 1991, Pavez et al. 2010). Their small size, fragility, and transparency have rendered small gelatinous zooplankton difficult to sample. Thus, their distribution and ecological impact are virtually unknown.

Due to the limitations in conventional net sampling, which destroys or disrupts most gelatinous zooplankton, many scientists have called for in situ approaches to resolve their distributions, including blue water diving, manned submersibles, remotely operated vehicles (ROVs), and towed camera systems (Hamner et al. 1975, Raskoff 2002, Haddock 2004). Diving and submersibles were used in early studies on gelatinous zooplankton (Hamner et al. 1975, Mackie \& Mills 1983, Madin 1988), but these techniques are less applicable for systematic studies of jellyfish due to limitations in duration and spatial coverage (diving) and operational cost (submersibles). ROVs have been used extensively to examine distributions of jellyfish (Silguero \& Robison 2000, Raskoff 2001) but require the careful maneuvering of the vehicle to traverse long distances. Furthermore, since many gelatinous zooplankton are small and transparent, they may be difficult to see and quantify accurately using frontlighting with vehicles such as submersibles and ROVs. One solution has been to use back-lighting to create silhouettes for imaging transparent organisms (Ortner et al. 1981, Samson et al. 2001).

Towed camera systems are considered best suited for fine (i.e. $\mathrm{m}$ to $100 \mathrm{~s}$ of $\mathrm{m}$ ) to coarse- (i.e. 1 to $100 \mathrm{~km}$ ) scale distributional studies, as they can easily sample over long distances without careful vehicle maneuvering (Graham et al. 2003). However, very few towed camera systems are capable of sampling sufficiently large volumes of water to quantify large, rare organisms such as jellyfish (but see Graham et al. 2003, Madin et al. 2006), and none has combined a large sampling volume with back-lit imaging for studying gelatinous zooplankton. The In Situ Ichthyoplankton Imaging System (ISIIS) is a towed-camera system with focused shadowgraph imaging and sufficiently large field-of-view that samples large volumes of water for quantitative measurement (size and abundance) of mesozooplankton (Cowen \& Guigand 2008). It has been used in various coastal environments to study the fine to coarse-scale distribution of plankton, including gelatinous zooplankton (McClatchie et al. 2012, Cowen et al. 2013, Greer et al. 2013).

Fronts and other mesoscale features are often sites of enhanced plankton biomass and aggregations of upper trophic level nekton (Owen 1981, Olson \& Backus 1985, Franks 1992, Bakun 2006), contributing disproportionally to regional productivity and trophic ecology. However, fronts can vary in terms of spatial extent and temporal duration, ranging from large, quasi-permanent fronts to transient fronts formed by mesoscale eddy filaments, which may be defined by gradients in temperature, density, or chlorophyll a (chl a) fluorescence (Castelao et al. 2006, Kahru et al. 2012). Mesoscale fronts are common in coastal areas, but are still poorly understood in terms of their oceanography and how they structure biological communities (Landry et al. 2012). While studies on the complex plankton community dynamics at a front have included mid-trophic level organisms, most have focused on fish and crustaceans (Backus et al. 1969, Angel 1989, Koubbi 1993, Pakhomov et al. 1994, Lara-Lopez et al. 2012). Gelatinous zooplankton, as iono- and osmo-conformers that adjust slowly to even small salinity gradients, also tend to aggregate at density discontinuities (Mills 1984). Large medusae and ctenophores are known to bloom and aggregate at convergent surface fronts (see review in Graham et al. 2001), but little is currently known about whether the strong effects of frontal dynamics similarly affect the small gelatinous zooplankton, particularly considering the broad trophic roles they play.

The California Current is a wide, moderately productive, eastern boundary current, offshore from a zone of seasonal wind-driven upwelling. Numerous small-scale interactions with the upwelling zone, combined with small mesoscale variability, produce many filaments, eddies, and fronts off the central California coast. South of Point Conception, where the angle of the coast changes and the California Current moves far offshore, the Southern California Bight (SCB) experiences less upwelling, and is bounded on the west by a series of submarine ridges and seamounts called the Santa Rosa-Cortes Ridge (SRR). The SRR is a site where an inshore, fast-moving poleward flow meets a slower, offshore equatorward flow resulting in a seasonally persistent convergent frontal feature (Todd et al. 2011). This mesoscale feature is generated by the meeting of a filament of the California Current with SCB water, which is a complex mixture including Inshore Countercurrent and Equatorial Pacific water (McClatchie et al. 2012).

A dense aggregation of a small narcomedusa, Solmaris rhodoloma, was observed at a convergent, mesoscale front at the SRR in the SCB (McClatchie et al. 2012). Here, we extend McClatchie et al.'s (2012) study to investigate the broader gelatinous zooplankton community at the SRR front. We test the 
expectation that, as with $S$. rhodoloma, the front would play a dominant role in the distributions of the other members of the gelatinous zooplankton community as well. To do so, we first describe the fine to sub-mesoscale distributions of 46 taxa of gelatinous zooplankton to identify assemblage structure and dynamics, and then examine relationships between organisms and the frontal and water column environments using a non-linear modeling technique.

\section{MATERIALS AND METHODS}

\section{Sampling site and instrumentation}

This study was conducted south of San Nicolas Island in the SCB on 15 to 17 October 2010 (Fig. 1). As described in McClatchie et al. (2012), a frontal feature within the SCB was detected using remotely sensed Moderate Resolution Imaging Spectroradiometer (MODIS) sea surface temperature (SST) data. The area with the highest SST gradients was selected as the sampling region, and within this area, the strongest SST gradients were located south of San Nicolas Island at the SRR. MODIS SST images were obtained on 26 September, 10 October, and 28 October 2010. An autonomous glider undulating between

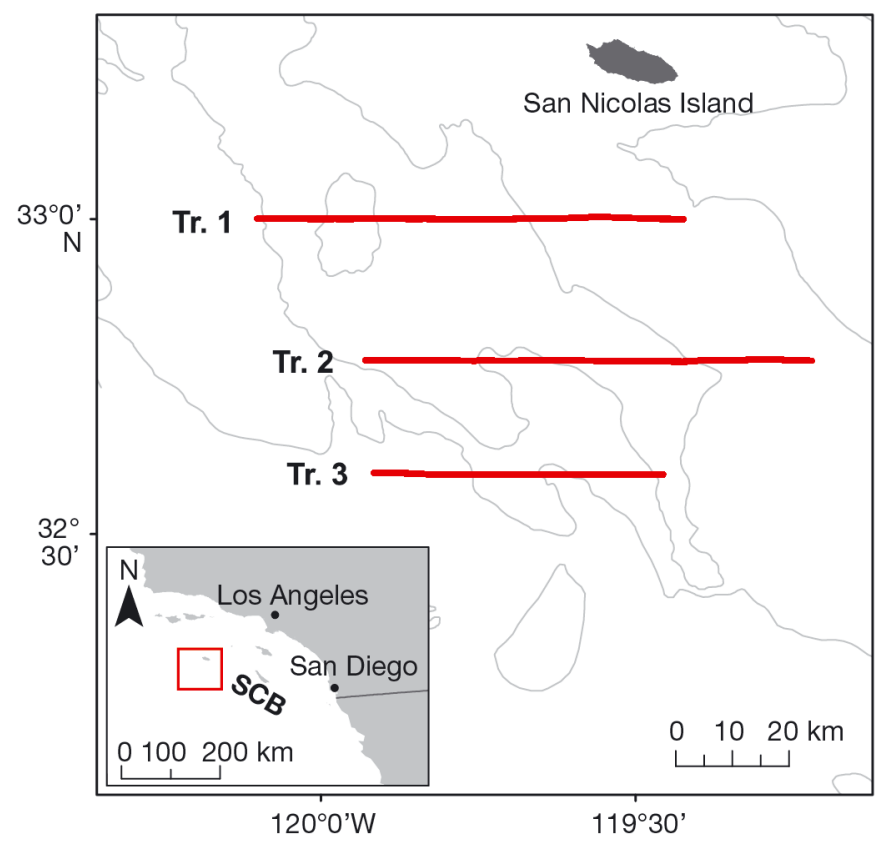

Fig. 1. Sampling transects in the Southern California Bight (SCB) during 15 to 17 October 2010. Transects were sampled on consecutive days, with Transect 1 sampled on 15 Oct and Transect 3 sampled on 17 Oct. Thin gray lines: $1000 \mathrm{~m}$ isobaths the surface and $500 \mathrm{~m}$ along CalCOFI line 90 (cf. Rudnick et al. 2004, Todd et al. 2011) also passed through the target frontal area from 2 to 8 October 2010 and provided an independent measurement of a subsurface feature which appeared to be a convergent front (see Section 3.2 in McClatchie et al. 2012).

We deployed the ISIIS to measure the horizontal and vertical distribution of the zooplankton and associated physical properties (temperature, salinity, oxygen, and chl a fluorescence) in the study area. ISIIS was towed behind the R/V 'Bell M. Shimada' at a speed of 5 knots $\left(2.5 \mathrm{~m} \mathrm{~s}^{-1}\right)$ and sampled the water column in a tow-yo fashion between the surface and ca. $130 \mathrm{~m}$ depth. We sampled the front in 3 parallel cross-front transects spaced ca. $25 \mathrm{~km}$ apart on consecutive days during the study period. Sampling from 17:00-23:36, 16:35-23:59, and 20:53-01:29 h (next day), we towed from east to west in the first 2 transects, and then from west to east in the last transect. These E-W transects were $\sim 45$ to $65 \mathrm{~km}$ in length and spanned a N-S distance of $\sim 50 \mathrm{~km}$ (Fig. 1). ISIIS sampled down and up along the 3 transects 24, 26, and 18 times over 63.25, 66.40, and $43.11 \mathrm{~km}$, respectively. Sensors on ISIIS measured conductivity, temperature, and depth (Sea-Bird Electronics 49 Fastcat CTD sensor), dissolved oxygen (DO) (SBE 43), and fluorometry (Eco FL-RT, Wetlabs chlorophyll-a fluorescence). A Doppler velocity log (DVL, Navquest 600) measured instrument velocity and pitch. ISIIS is equipped with a 2048-pixel line scan camera (Dalsa Piranha 2 P2-22-02k40) with a $13 \mathrm{~cm}$ field-of-view, $50 \mathrm{~cm}$ depth-of-field, and $66 \mu \mathrm{m}$ pixel resolution. The imaging output is recorded as a continuous image that is parsed into equivalent image frames $(2048 \times 2048$ pixels $)$ at 17 frames $\mathrm{s}^{-1}$. Traveling at a mean velocity of $2.47 \mathrm{~m} \mathrm{~s}^{-1}$, ISIIS sampled the water column at $166 \mathrm{l} \mathrm{s}^{-1}$. Sampling volumes for Transects 1 to 3 were 4001, 4428 and $2696 \mathrm{~m}^{-3}$, respectively, totaling $11125 \mathrm{~m}^{-3}$, although for this study we sub-sampled for downcasts only $\left(5450 \mathrm{~m}^{-3}\right.$ water). The combination of a fine pixel resolution with a large sampling volume on ISIIS allows for the simultaneous resolution of particles as small as $700 \mu \mathrm{m}$ (e.g. small copepods and appendicularians) as well as larger mesozooplankton within the 5 to $13 \mathrm{~cm}$ size range (Cowen et al. 2013).

\section{Image analysis}

Analysis of ISIIS images was done manually, except for 1 taxonomic group (Ctenophora), which was analyzed with assistance from an image segmenta- 
tion program. All images from each downcast were visually quantified for siphonophores, hydromedusae, and doliolids. Abundances of Solmaris rhodoloma were reported previously (McClatchie et al. 2012). Due to high abundances, appendicularians were sub-sampled and quantified in one-fifth of every 20th image. Within the hydromedusae, siphonophores, and ctenophores, individual organisms were identified to the lowest possible taxonomic group, many of which included species-level identifications. Species- or genus-level classifications were verified by taxonomic experts. Doliolids were identified only to order, and appendicularians to class.

Ctenophores were analyzed in every image in all downcasts with the assistance of the ISIIS image segmentation software (Tsechpenakis et al. 2007, 2008; downloaded from http://cs.iupui.edu/ gavriil/vital/ MVISIIS). The segmentation software identifies and extracts regions of interest (ROIs) from raw images by first eliminating the noise and then using a 1st order Conditional Random Field to detect targets. We optimized the program for segmenting ctenophores (using the following inputs: filter $=20.4$, length of major axis $=13$, area $=1.7$ ), achieving a $>90 \%$ segmentation accuracy rate. We then sorted the ctenophores from the other ROIs and identified them manually to the lowest possible taxonomic group.

\section{Data analysis}

\section{Physical environment}

Environmental variables from ISIIS sensors (temperature, salinity, chl a fluorescence, DO, and calculated seawater density) were interpolated throughout the water column to create background maps. For simplicity, we chose to use a simple interpolation based on Euclidean distances. To do so, we had to scale the horizontal and vertical coordinates to isotropy (original values of environmental variables were not changed). First, we estimated the anisotropy between environmental variables in the vertical and horizontal direction by inspecting directional variograms for each variable to find the most appropriate scaling factor for the coordinates (1800:1). Then, we rescaled the horizontal coordinate according to the scaling factor and linearly interpolated between casts. R packages 'gstat' and 'akima' were used. (Pebesma 2004, Akima et al. 2013).

In this study, the front was primarily delineated by salinity, and defined as the location of the greatest rate of change in salinity values. Isohalines between
33 and 34 were inspected, and the locations where the isohalines were closest together were delineated as the front.

Physical data (non-interpolated environmental variables and location data) and biological counts were both placed into $1 \mathrm{~m}$ depth bins and then matched with each other using the sample time stamp. The concentration of each organism per bin $\left(c_{b}\right.$ ino. of ind. $\mathrm{m}^{-3}$ ) was calculated from counts $\left(a_{b}\right)$ and volume sampled $\left(\mathrm{Vol}_{b}\right)$ :

$$
c_{b}=\frac{a_{b}}{V o l_{b}}=\frac{a_{b}}{0.13 \times 0.50 \times v_{b}\left(t_{b f}-t_{b \mathrm{i}}\right)}
$$

where 0.13 is the ISIIS vertical field of view in $\mathrm{m}, 0.5$ is the ISIIS depth of field in $\mathrm{m}, v_{b}$ is the average instrument velocity per time bin $\left(\mathrm{m} \mathrm{s}^{-1}\right), t_{b \mathrm{f}}$ and $t_{b \mathrm{i}}$ the final and initial times when ISIIS crossed each depth bin. This differs from McClatchie et al. (2012) in that previously, concentrations of organisms were calculated using counts per $1 \mathrm{~m}^{3}$ along-path sampling volume, so the depth range for each bin varied by instrument descent speed. The current method standardizes to volume $\mathrm{m}^{-1}$ depth bin.

\section{Species distribution and assemblage analysis}

All species were ranked according to total abundance and percent present in the water column. Those that were present in $<1 \%$ of total depth bins and $<0.02 \%$ of the total population were considered 'Rare' and no further analyses were performed. Multi-species unknown ctenophores and hydromedusae were also excluded. Single-species unknown hydromedusae were included, as well as the 'very small hydromedusae' (vsh). A simple 'Frontal Aggregation Factor' (FAF), defined as mean concentration within the front / mean concentration outside the front, was calculated for all organisms. KruskalWallis tests were performed on the mean concentration of organisms (1) inside vs. outside of the front, and (2) in the front vs. east of the front. Large and small S. rhodoloma (McClatchie et al. 2012) were distinguished for initial abundance and aggregation tests, but were grouped together for all further tests.

To examine the spatial co-occurrence of species, we performed a correspondence analysis (CA) on log-transformed concentration data, and then used hierarchical clustering with Ward's method on the first $4 \mathrm{CA}$ axes to identify assemblages. The CA biplot did not show a horseshoe effect, so Detrended Correspondence Analysis (DCA) was not necessary. The CA was conducted in R v.3.0.1 (R Development 
Core Team 2013) using package 'vegan' (Oksanen et al. 2013). To look at positive and negative associations of species with each other, we constructed a correlation heatmap using the non-parametric Spearman's rank correlation coefficient.

\section{Species distribution modeling}

Species-environment relationships were evaluated using boosted regression trees (BRTs), an ensemble statistical method that combines regression trees with boosting, a machine learning technique (Elith et al. 2008). The R package 'gbm' was used (Ridgeway 2013). BRTs optimize predictive performance using the iterative development of a large group of small regression trees constructed with random subsets of the data. We chose to use BRTs because most organisms in our dataset exhibited non-monotonic, non-linear relationships to environmental gradients, thus rendering linear models inappropriate. Tree-based methods, which include BRTs, also provide an estimate of the relative influence of each environmental variable to species distributions (Friedman 2001, Ridgeway 2012). Models were constructed with 6 explanatory variables: front (a categorical variable indicating location with respect to the front), and 5 continuous variables (depth, temperature, salinity, oxygen, and fluorometry). Since most environmental variables were correlated with depth, depth was explicitly included in the model to account for variation that was attributed to depth and not the frontal feature. We used learning rates as close to the recommend 0.01 to 0.001 range as possible, a maximum of 10000 trees, and 5fold cross validation. The interaction depth of each tree was set to 3 . Using fitted model values, pseudo- $\mathrm{R}^{2}$ values were calculated as 1 - mean squared error / total squared error. Species 'maps' were then plotted using the results of the BRTs: concentrations were plotted by depth and longitude and overlaid onto an interpolated plot of the variable with the highest contribution to the model.

\section{RESULTS}

\section{Physical environment}

The physical environment in the study area was dominated by a salinity-driven front delineated by the 33.3 and 33.45 isohalines (Fig. 2). The temperature profile was relatively similar on each side of the front (see Fig. S1 in the Supplement at www.int-res. com/articles/suppl/m510p129_supp.pdf). Maximum chl a fluorescence occurred on the east side of the front, approximately 20 to $30 \mathrm{~km}$ from the front (Fig. S2). DO was higher in the waters to the west of the front (Fig. S3). There was a slight delay in the DO sensor, resulting in an offset of 3 to $6 \mathrm{~m}$ between the downcasts and upcasts (Fig. S3), though within the downcasts, the values showed no step structure. In general, the waters to the west of the front were marked by low salinity, high DO and low chl a. The waters to the east of the front were marked by high salinity, low DO and high surface chl a.

\section{Species abundance}

A total of 664650 appendicularians, 107626 hydromedusae, 11934 siphonophores, 4425 doliolids, and 4413 ctenophores were counted in ca. 700000 frames. Mean concentrations $( \pm \mathrm{SD})$ were $105.45 \pm 257.6,0.81 \pm 11.2$, $0.28 \pm 1.3,0.98 \pm 4.5$, and $0.06 \pm 0.44$ ind. $\mathrm{m}^{-3}$, respectively. Hydromedusae were split into 22 taxa, including 7 nar-

comedusae, 6 trachymedusae, 1 lep-
Fig. 2. Interpolated salinity profile of the sampled transects in the Southern California Bight. Distance (in km) is measured along each transect. Top: Transect 1; middle: Transect 2; lower: Transect 3. Contour lines mark the 33.3 and 33.45 isohalines. Tick marks indicate the starting and ending locations of each tow-yo cast. Biological data for the downcasts only were analyzed 
tomedusa, 1 anthomedusa, and 6 unknown species, including the catch-all vsh group. Siphonophores were classified into 9 taxa, consisting of 5 calycophoran and 4 physonect species. There were 12 species of ctenophores and 1 unknown group. All 3 major appendicularian families were present in the study area, but were not distinguished here. Doliolids were also lumped into 1 group. In total, 46 gelatinous zooplankton taxa were quantified (Fig. 3).

The most abundant organisms by far were the appendicularians, followed by Solmaris rhodoloma, vsh, and Liriope tetraphylla (all hydromedusae). The most abundant siphonophore was Sphaeronectes sp., which consisted of over 95\% Sphaeronectes koellikeri and the remainder Sphaeronectes fragilis. The most abundant ctenophore was the lobate Ocyropsis maculata. A total of 16 rare taxa were excluded from further analysis. Excluding the unknown ctenophores and 1 group of unknown hydromedusae, 28 taxa were further analyzed (Table 1).

FAF values, along with the Kruskal-Wallis tests, showed that most organisms were not aggregated at the front (Table 1). Since more organisms were present to the east of the front (SCB waters) than the west (California Current waters), we also calculated an

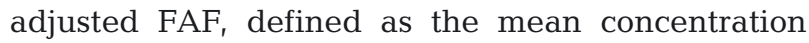
within the front / mean concentration to the east of the front (data not shown). All organisms with FAF $<2$ also had an $\mathrm{FAF}_{\text {adj }}<1.25(\mathrm{n}=40)$, which means that organisms within the front were only $25 \%$ more abundant than inshore (east) of the front. We considered those to be 'not aggregated' at the front. Six organisms had FAF values between 2 and 2.35 and $\mathrm{FAF}_{\text {adj }}<2$, but only 3 (doliolids, Solmaris sp. 2, and Aegina citrea) were significant in both Kruskal-Wallis tests; these were considered 'mildly aggregated'. Solmundella bitentaculata and h15 (hydromedusa) were 'moderately aggregated,' with FAF between
3 and 3.5. Large $S$. rhodoloma was 'highly aggregated,' with FAF $=3.9$ and $\mathrm{FAF}_{\mathrm{adj}}=11.9$. Out of all sampled taxa, 43 were not aggregated, 5 were mildly to moderately aggregated, and only 1 taxon was highly aggregated at the front.

\section{Assemblage analysis}

CA was performed on the 28 taxa to evaluate species co-occurrence. CA results were then evaluated using cluster analysis, which revealed 4 assemblages and 2 outlier species (Fig. 4). The largest assemblage, A, comprised 13 taxa including the pelagic tunicates, 6 hydromedusae, 2 ctenophores, and a siphonophore. Assemblage B consisted of only siphonophores and ctenophores. Assemblage C contained 2 ctenophores, and assemblage D had 2 siphonophores and 3 hydromedusae. The outliers were also hydromedusae. Hydromedusae and tunicates tended to group together, and siphonophores and ctenophores tended to group together.

Relationships among taxa and among assemblages were further examined by the correlation heatmap, which shows correlations between taxa as well as positive (co-occurrence) and negative (absence/ avoidance) relationships (Fig. 4). Correlation strength was greatest in assemblage A (mean $\rho=$ 0.26 ) and declined in subsequent assemblages (mean $\rho=0.18,0.08,0.04$ for assemblage B, C, and D, respectively). The strongest correlations in assemblage A were between $S$. rhodoloma and vsh ( $\rho=$ $0.62, \mathrm{p}<0.01$ ), and $S$. rhodoloma and L. tetraphylla $(\rho=0.55, p<0.01)$. Though Muggiaea atlantica clustered into assemblage $B$, it exhibited strong positive correlations with assemblage A taxa. The strongest negative correlations were between $O$. maculata and S. rhodoloma $(\rho=-0.18, \mathrm{p}<0.05)$ and vsh $(\rho=-0.16$,

Fig. 3. (a-av) In Situ Ichthyoplankton Imaging System (ISIIS) images of all taxa found in the Southern California Bight. (a-t) Hydromedusae: (a) Liriope tetraphylla; (b) Solmaris rhodoloma; (c) very small hydromedusae; (d) Solmundella bitentaculata; (e) h15; (f) Rhopalonema velatum; (g) Pegantha sp. 1; (h) Haliscera conica; (i) Aglantha sp. (likely A. digitale); (j) Haliscera sp. 2; (k) Solmaris sp. 2; (l) Arctapodema sp.; (m) unknown hydro 2; (n) Pegantha sp. 2; (o) Aegina aff. citrea; (p) Annatiara affinis; (q) Eutonia scintillans; (r) unknown hydro 1; (s) Pandeidae; (t) unknown hydro 3. (u-ae) Siphonophores: (u) Chelophyes sp.; (v) Lensia multicristata; (w) Sphaeronectes fragilis; (x) Nanomia bijuga; (y) Forskalia sp.; (z) Agalma elegans; (aa) Muggiaea atlantica; (ab) Sphaeronectes koellikeri; (ac) Cordagalma sp.; (ad) Lilyopsis rosea; (ae) Prayidae. For siphonophores, the 2 Sphaeronectes species (w,ab) were grouped together, though the majority $(>95 \%)$ were $S$. koellikeri. The diphyid siphonophores other than $M$. atlantica were grouped together, and this group is likely dominated by 2 taxa $(\mathrm{u}, \mathrm{v})$. (af-ar) Ctenophores: (af) Haeckelia beehlri; (ag) juvenile lobata; (ah,ai) larval lobates; (aj,ak) Ocyropsis maculata, see possible developmental sequence from ah-ak; (al) Hormiphora californiensis; (am) Velamen parallelum; (an) undescribed Mertensiidae; (ao) Bolinopsis vitrea; (ap) Beroida; (aq) Thalassocalyce inconstans; (ar) Charistephane sp. Not pictured: Bolinopsis infundibulum and Pleurobrachia sp. (as-av) Pelagic tunicates: (as) doliolid; (at) Oikopleuridae appendicularian house; (au) Fritillaridae appendicularian; and (av) Kowalevskiidae appendicularian. 


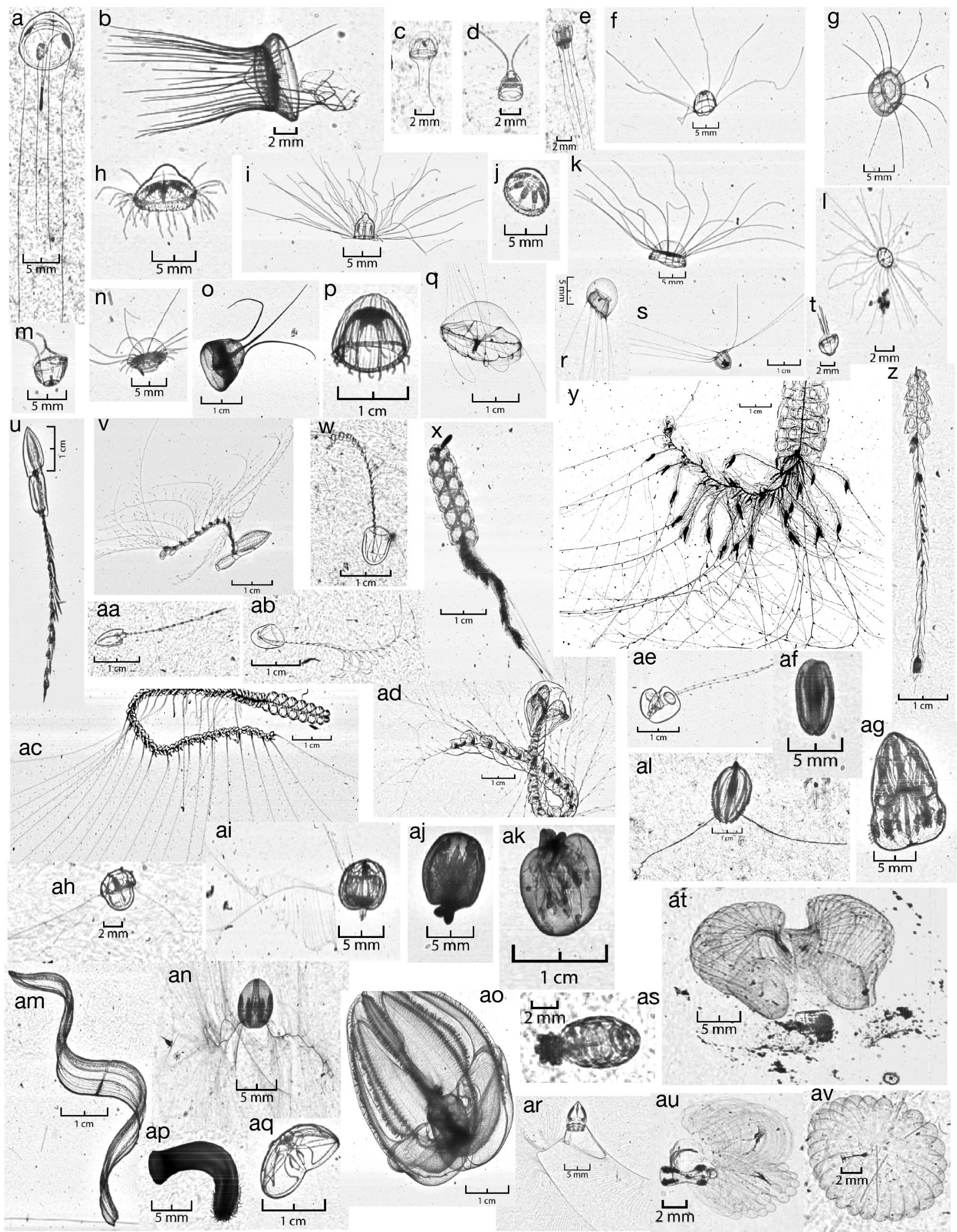


Table 1. Abundances and concentrations for all sampled taxa, binned into $1 \mathrm{~m}$ depth bins. Dark grey shading indicates rare taxa and light grey shading indicates the 2 unknown groups that were not included in further analyses. Table columns indicate: percent of the total sampled water column in which species was found, maximum concentration in a $1 \mathrm{~m}$ depth bin, maximum counts in a $1 \mathrm{~m}$ depth bin, total counts, the frontal aggregation factor (FAF), significance of a Kruskal-Wallis (K-W) test of mean concentrations in vs. out of the front (i/o F), and the significance of a K-W test of mean concentrations in the front vs. east of the front $(\mathrm{F} / \mathrm{E})$. The second $\mathrm{K}-\mathrm{W}$ test significance is reported because the eastern (inshore) portion of the sampling region had more organisms overall. Solmaris rhodoloma (all) was included as well as the large ( $>5 \mathrm{~mm}$ bell diameter) and small ( $<5 \mathrm{~mm}$ bell diameter) size fractions. FAF is calculated as mean concentration inside the front / mean concentration outside the front. FAF values $>3$ are in bold. K-W test significance level symbols: ${ }^{*} p \leq 0.1,{ }^{* *} p \leq 0.05$, and ${ }^{* * *} p \leq 0.01$. Short dash $(-)$ is not significant

\begin{tabular}{|c|c|c|c|c|c|c|c|c|}
\hline Taxon & Group & \% Present & $\begin{array}{l}\text { Max conc. } \\
\left(\text { no. } \mathrm{m}^{-3} \text { ) }\right.\end{array}$ & $\begin{array}{l}\text { Max counts } \\
\left(\text { no. } \mathrm{m}^{-3}\right)\end{array}$ & $\begin{array}{l}\text { Total } \\
\text { abund. }\end{array}$ & FAF & $\begin{array}{l}\mathrm{K}-\mathrm{W} \\
(\mathrm{i} / \mathrm{o} \mathrm{F})\end{array}$ & $\begin{array}{l}K-W \\
(F / E)\end{array}$ \\
\hline Appendicularians & Tunicates & 24.15 & 3695.51 & 8700 & 644650 & 0.99 & ${ }^{*}$ & $* * *$ \\
\hline Solmaris rhodoloma & Hydromedusae & 19.23 & 861.77 & 2300 & 79350 & 2.75 & $* * *$ & $* *$ \\
\hline Large size & & 8.96 & 772.11 & 775 & 25450 & 3.91 & $* * *$ & $* * *$ \\
\hline Small size & & 16.58 & 757.72 & 2010 & 54010 & 2.27 & $* * *$ & - \\
\hline $\begin{array}{l}\text { vsh ('very small } \\
\text { hydromedusae') }\end{array}$ & Hydromedusae & 15.64 & 156.23 & 394 & 15347 & 2.17 & $* * *$ & - \\
\hline Liriope tetraphylla & Hydromedusae & 15.47 & 92.33 & 258 & 7814 & 1.58 & $* * *$ & - \\
\hline Sphaeronectes sp. & Siphonophores & 28.63 & 28.56 & 14 & 4717 & 1.29 & $* * *$ & - \\
\hline Doliolids & Tunicates & 10.24 & 78.46 & 88 & 4425 & 2.33 & $* * *$ & $* * *$ \\
\hline Muggiaea atlantica & Siphonophores & 14.31 & 23.29 & 39 & 2686 & 1.45 & $* * *$ & - \\
\hline Nanomia bijuga & Siphonophores & 19.69 & 22.66 & 11 & 2596 & 1.01 & $* *$ & $* * *$ \\
\hline Ocyropsis maculata & Ctenophores & 14.56 & 12.71 & 10 & 1820 & 1.08 & $* *$ & $* * *$ \\
\hline Solmundella bitentaculata & Hydromedusae & 8.37 & 20.63 & 29 & 1727 & 3.44 & $* * *$ & $* * *$ \\
\hline h15 & Hydromedusae & 5.51 & 37.03 & 45 & 1245 & 3.22 & $* * *$ & $* * *$ \\
\hline Diphyidae & Siphonophores & 8.64 & 9.74 & 11 & 1047 & 1.06 & - & - \\
\hline Beroida & Ctenophores & 6.14 & 19.77 & 8 & 703 & 0.89 & - & $* * *$ \\
\hline Hormiphora californiensis & Ctenophores & 4.37 & 9.76 & 10 & 517 & 1.34 & $* *$ & - \\
\hline Larval Lobata & Ctenophores & 4.65 & 10.52 & 5 & 503 & 0.93 & - & $* * *$ \\
\hline Agalma elegans & Siphonophores & 3.83 & 11.77 & 5 & 452 & 1.77 & $* * *$ & $* *$ \\
\hline Unknown-hydro & Hydromedusae & 2.62 & 19.6 & 18 & 390 & 1.33 & $* * *$ & $* * *$ \\
\hline Pegantha sp. 1 & Hydromedusae & 2.28 & 11.06 & 9 & 333 & 0.49 & - & $* * *$ \\
\hline Rhopalonema velatum & Hydromedusae & 2.76 & 4.7 & 3 & 267 & 1.26 & - & - \\
\hline Velamen parallelum & Ctenophores & 2.49 & 5.7 & 3 & 243 & 1.41 & $* * *$ & ${ }^{*}$ \\
\hline Haliscera conica & Hydromedusae & 2.45 & 5.75 & 3 & 235 & 1.68 & $* * *$ & - \\
\hline Lilyopsis rosea & Siphonophores & 2.11 & 6.73 & 2 & 196 & 1.27 & - & - \\
\hline Aglantha sp. & Hydromedusae & 1.85 & 5.17 & 4 & 195 & 0.98 & - & $* * *$ \\
\hline Thalassocalyce inconstans & Ctenophores & 1.83 & 5.21 & 2 & 174 & 1.36 & * & - \\
\hline Haliscera sp. 2 & Hydromedusae & 1.63 & 4.96 & 5 & 164 & 1.53 & ** & - \\
\hline Solmaris sp. 2 & Hydromedusae & 1.44 & 9.26 & 4 & 160 & 2.02 & $* * *$ & $* *$ \\
\hline Prayidae & Siphonophores & 1.51 & 5.11 & 2 & 144 & 0.49 & $* * *$ & $* * *$ \\
\hline Unknown & Ctenophores & 1.35 & 4.99 & 3 & 128 & 1.2 & - & ${ }^{*}$ \\
\hline Mertensiidae, undesc & Ctenophores & 1.27 & 5.72 & 2 & 117 & 1.53 & $* * *$ & - \\
\hline Haeckelia beehlri & Ctenophores & 1.06 & 4.32 & 2 & 97 & 0.85 & - & - \\
\hline Cordagalma sp. & Siphonophores & 0.94 & 5.13 & 2 & 87 & 1.36 & - & - \\
\hline Juvenile Lobata & Ctenophores & 0.82 & 4.11 & 2 & 78 & 1.05 & - & - \\
\hline Unk-hydro-3 & Hydromedusae & 0.69 & 4.09 & 3 & 68 & 0.67 & - & - \\
\hline Arctapodema sp. & Hydromedusae & 0.67 & 4.4 & 2 & 63 & 0.47 & $*$ & $* * *$ \\
\hline Eutonia scintillans & Hydromedusae & 0.58 & 4.84 & 3 & 57 & 1.25 & - & - \\
\hline Annatiara affinis & Hydromedusae & 0.51 & 3.86 & 2 & 48 & 0.85 & - & - \\
\hline Pegantha sp. 2 & Hydromedusae & 0.42 & 6.04 & 3 & 45 & 0.33 & - & - \\
\hline Aegina aff. citrea & Hydromedusae & 0.46 & 2.89 & 2 & 44 & 2.02 & * & $* *$ \\
\hline Pandeidae & Hydromedusae & 0.31 & 3.37 & 1 & 28 & 1.33 & - & - \\
\hline Unk-hydro-2 & Hydromedusae & 0.24 & 2.19 & 2 & 24 & 0.45 & - & - \\
\hline Unk-hydro-1 & Hydromedusae & 0.23 & 5.21 & 2 & 22 & 0.12 & * & * \\
\hline Bolinopsis sp. & Ctenophores & 0.1 & 2.38 & 1 & 9 & 1.46 & - & - \\
\hline Charistephane sp. & Ctenophores & 0.1 & 2.81 & 1 & 9 & 1.39 & - & - \\
\hline Dryodora glandiformis & Ctenophores & 0.1 & 3.69 & 1 & 9 & 1.1 & - & - \\
\hline Forskalia sp. & Siphonophores & 0.1 & 2.24 & 1 & 9 & 2.35 & - & - \\
\hline Pleurobrachia sp. & Ctenophores & 0.04 & 1.17 & 3 & 6 & 0 & - & - \\
\hline
\end{tabular}




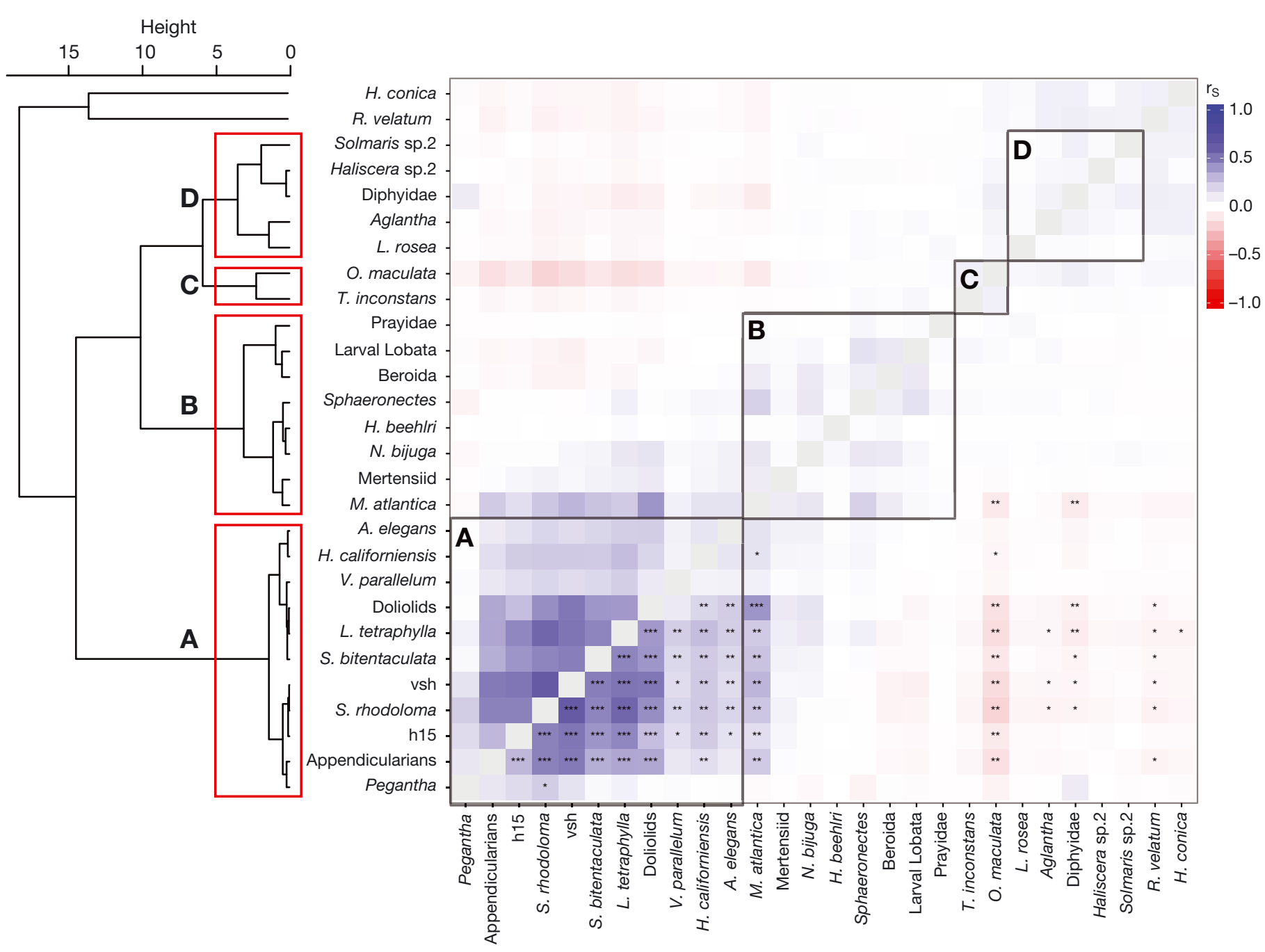

Fig. 4. Assemblages and community-level relationships between gelatinous zooplankton. Left: cluster dendrogram of the first 4 axes of the canonical correspondence (CA) species scores. Four main groups are indicated in boxes. Right: correlation heatmap constructed using the non-parametric Spearman's rank correlation coefficient $\mathrm{r}_{\mathrm{S}}$. Blue: positive correlation; red: negative correlation. Shading indicates strength of correlation. Assemblage groupings from CA results are marked in boxes. The level of statistical significance for each correlation coefficient is given in the lower triangle: ${ }^{* * *} p<0.01,{ }^{* *} p<0.05$, and ${ }^{*} p<0.1$

$\mathrm{p}<0.05)$. Except for some assemblage B taxa, most other organisms exhibited weak negative correlations (though some significant at $\mathrm{p}<0.05$ ) with assemblage A taxa (Fig. 4).

\section{Gelatinous zooplankton and their physical environment}

There are notable trends in the location and environmental conditions in which different taxa were found (Fig. 5). Of the gelatinous zooplankton, the taxa that occupied the shallowest and deepest areas were the hydromedusae. Both groups of siphonophore and ctenophore species were present in the mid-depths, though as a group, the siphonophores tended to aggregate in the upper mid-depths compared to ctenophores, which occupied the lower middepths. They were also present in a broad range of temperatures and DO levels. All organisms occupied waters within a narrow range of salinities. By depth, assemblage A was shallowest (mean $16.5 \mathrm{~m}$ ), followed by B, C, and D (mean 48.9, 90.0, $84.4 \mathrm{~m}$, respectively); the 2 outliers had a mean depth of $102.2 \mathrm{~m}$. Assemblages were generally organized by depth-related factors rather than factors that varied along the horizontal plane.

To further evaluate the relative influence of the environmental variables on species distributions, statistical modeling was performed on all 28 taxa using BRTs, although only 17 taxa were present in sufficient numbers for accurate modeling. The 11 taxa 


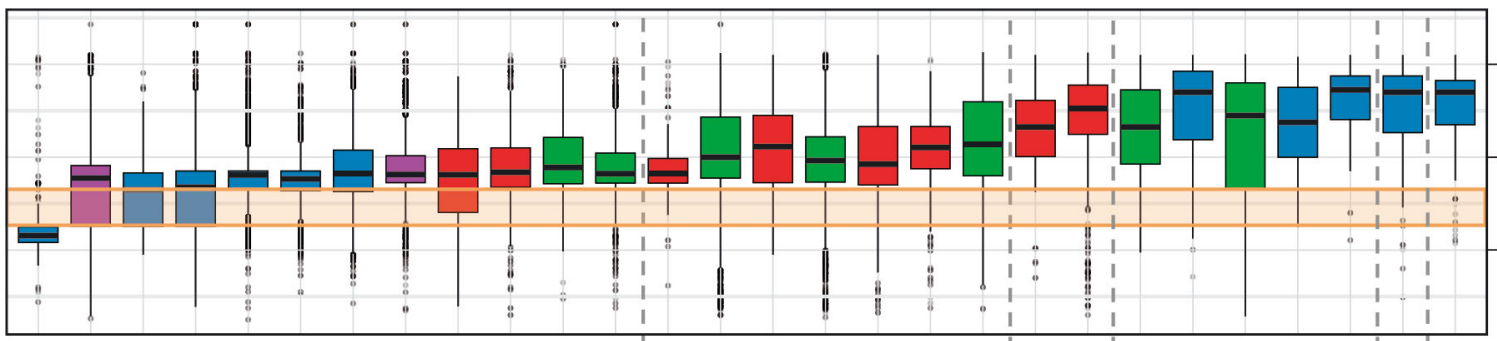

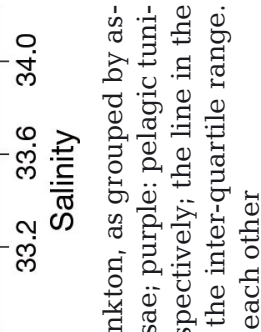

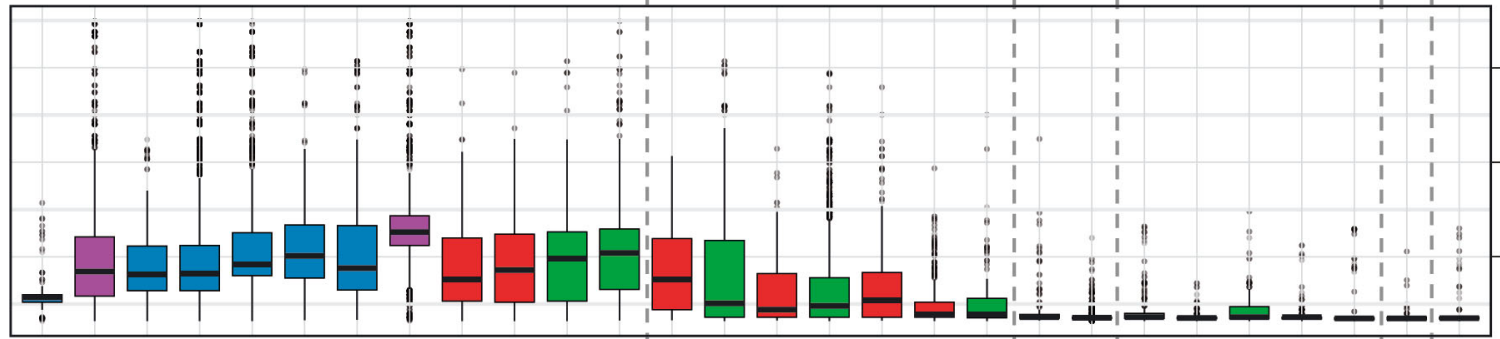

준 궝

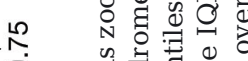
० $\sum_{0} \cdot \begin{array}{ll}0 \\ 0 \\ 0\end{array}$ ○ 흥 은

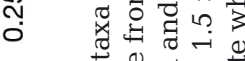
要

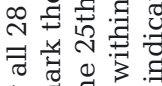

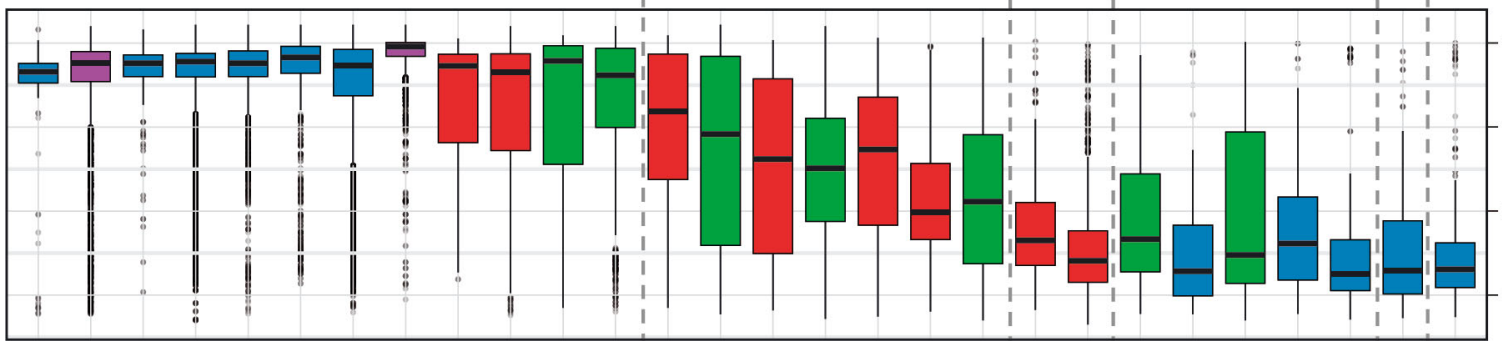

氙 贯 I छ

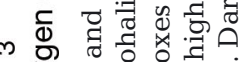
तิ 赵

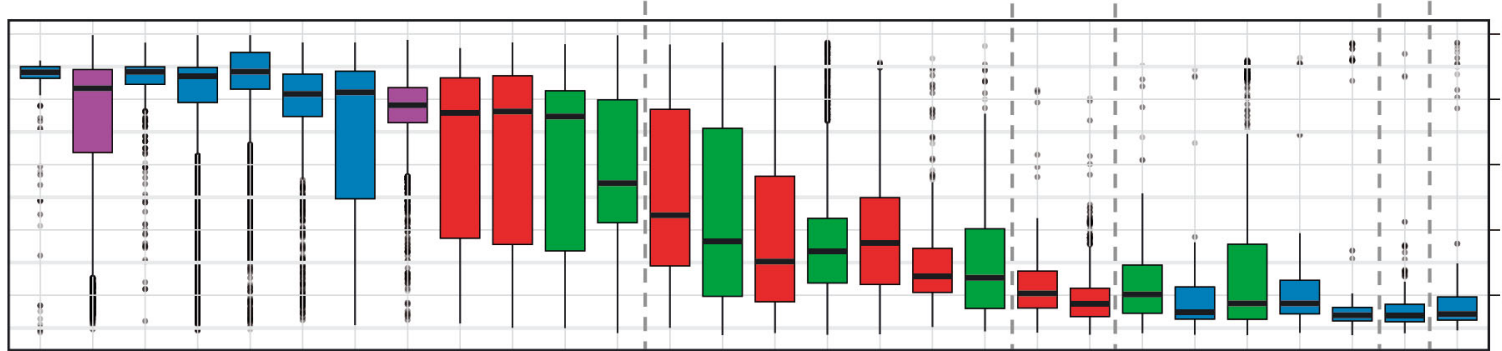

$\stackrel{\infty}{\sim}$ जी

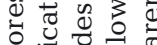

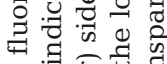
- $\quad$ 政 $\checkmark$ O

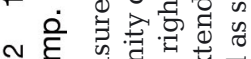

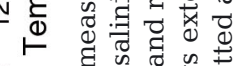
우 $\quad \longrightarrow$ 웜

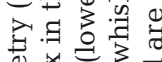

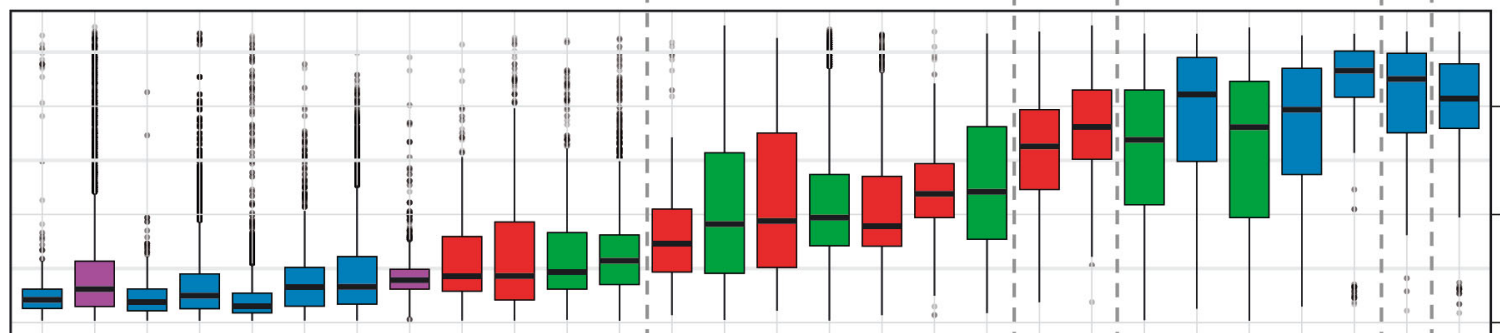

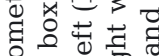
으 $\bar{\Xi}$

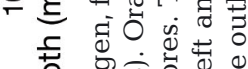

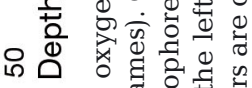
뭉

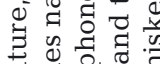

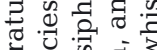
के

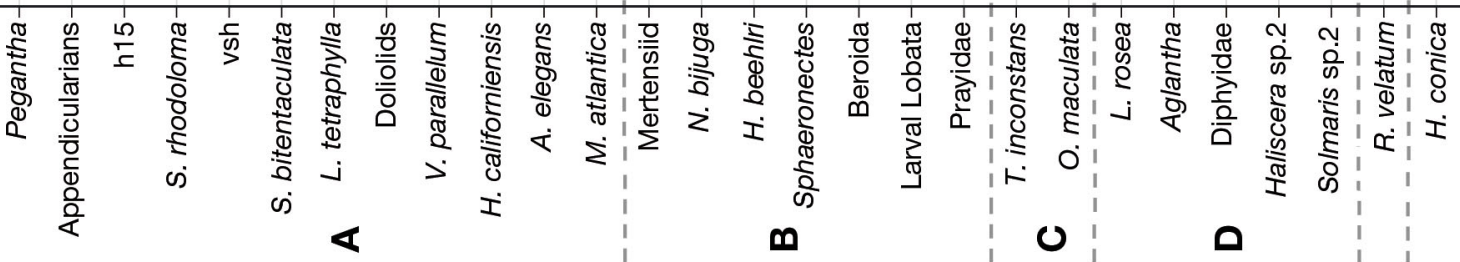
वृ 牙范

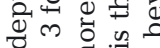

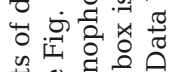
웅 屯

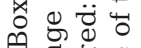
का

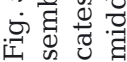


with low model $\mathrm{R}^{2}$ values $(<0.11)$, with the exception of the larval lobates, were only found in maximum concentrations of $<9$ ind. $\mathrm{m}^{-3}$. The remaining 17 taxa were found in densities $>9$ ind. $\mathrm{m}^{-3}$ and reasonable models could be fit to them. Of the modeled taxa, the number of trees fit (Table S1) ranged from 4637 for Solmaris sp. 2, to 9996 for both Beroida and O. maculata. The majority of models had more than 6000 trees. Model $\mathrm{R}^{2}$ values ranged from 0.13 for Hormiphora californiensis to 0.93 for S. rhodoloma (Fig. 6). Modeled taxa include 10 of 11 organisms in assemblage A, 4 of 8 in assemblage B, 1 of 2 in assemblage $\mathrm{C}$, and 2 of 5 in assemblage $\mathrm{D}$.

BRT model results show that overall, temperature and depth had the highest relative influence for the largest number of organisms (Fig. 6). Temperature was the most important variable for 6 species, chl a was most important for 4 species, depth for 4 species, DO for 2 species, and salinity for only 1 species. Groupings by assemblage revealed that the first half of assemblage $\mathrm{A}$ was primarily influenced by temperature and depth, and the second half of A through C (with some exceptions) was primarily influenced by chl a fluorescence and DO.

BRT modeling results showed high consistency in the relative influence of variables within broad taxonomic groups, regardless of assemblage affiliation (Fig. 6). The most influential variables for hydromedusae were temperature (mean 27\%) and depth (mean 25\%). Appendicularians were also primarily associated with depth (45\%) but doliolids with chl a (35\%). Siphonophores were primarily associated with DO (mean 26\%) and chl a (mean $22 \%)$. Model results for ctenophores were more varied: $H$. californiensis was associated with $\mathrm{chl}$ a $(28 \%)$ and temperature $(27 \%)$, Beroida with temperature $(23 \%)$, and O. maculata with DO (48\%).

Position relative to the front, a categorical variable, was the least influential of all the environmental variables, and did not factor in as most important for any of the 17 taxa. Salinity ranked highest in only 1 model (diphyidae), and its average contribution $(13 \%)$ was greater than that of the front position $(5.9 \%)$. Compared to other groups,

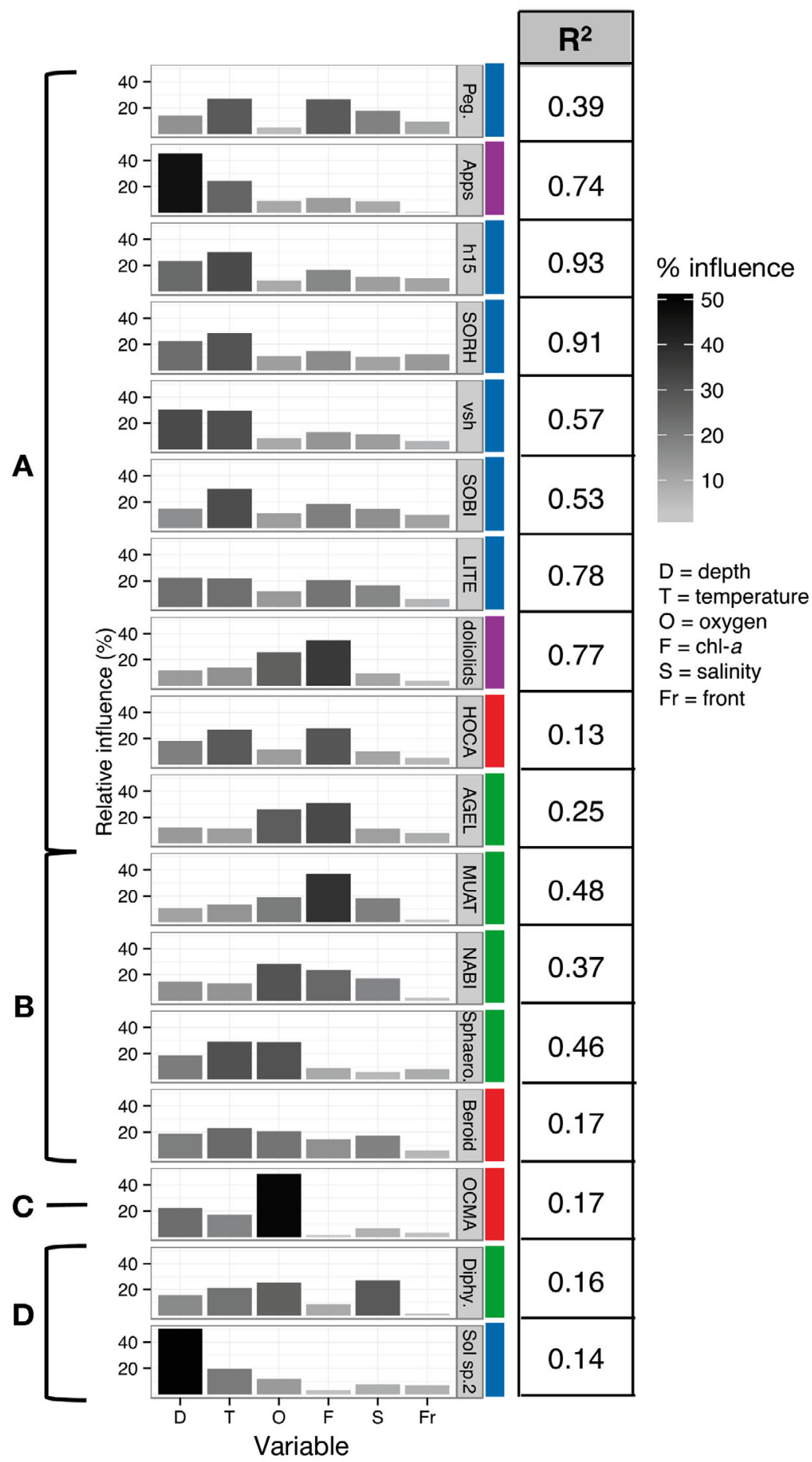

Fig. 6. Results of the boosted regression tree (BRT) analysis for 17 taxa of gelatinous zooplankton, with associated model $\mathrm{R}^{2}$ values, grouped by assemblages. Bar plots show the percent influence of each variable $(\mathrm{D}=$ depth, $\mathrm{T}$ = temperature, $\mathrm{O}=$ oxygen, $\mathrm{F}=$ chl a fluorescence, $\mathrm{S}=$ salinity, $\mathrm{Fr}=$ front). Blue: hydromedusae; purple: pelagic tunicates; red: ctenophores; green: siphonophores. Peg. = Pegantha; Apps = Appendicularians; $\mathrm{SORH}=$ Solmaris rhodoloma $;$ vsh $=$ very small hydromedusae; SOBI = Solmundella bitentaculata $;$ LITE $=$ Liriope tetraphylla; HOCA = Hormiphora californiensis; AGEL = Agalma elegans; $\mathrm{MUAT}=$ Muggiaea atlantica $;$ NABI $=$ Nanomia bijuga $;$ Sphaero. $=$ Sphaeronectes; Beroid $=$ Beroida $;$ OCMA = Ocyropsis maculata $;$ Diphy = Diphyidae $;$ Sol sp. $2=$ Solmaris sp. 2 
siphonophores were most influenced by salinity (mean 16\%), but this still only ranked as fourth (out of 6) most important variable to the group. Front position contributed the least to models of appendicularians $(0.87 \%)$, diphyidae $(1.8 \%)$ and $M$. atlantica $(1.9 \%)$, and most to 3 hydromedusae (h15 and $S$. bitentaculata, both $10 \%$; S. rhodoloma, $12 \%$ ) and Sphaeronectes sp. (8.2\%). Large S. rhodoloma was also modeled separately (though not shown) and had salinity $(18 \%)$ as the second most important variable and the front as the fourth $(15 \%)$ most important variable. Overall, the influence of the front in BRT models was lowest for pelagic tunicates, and highest for hydromedusae. Appendicularians, O. maculata and Solmaris sp. 2 were least associated with both salinity and the front in their models.

Based on model results, abundances of 6 representative taxa (3 hydromedusae, doliolids, 1 siphono-

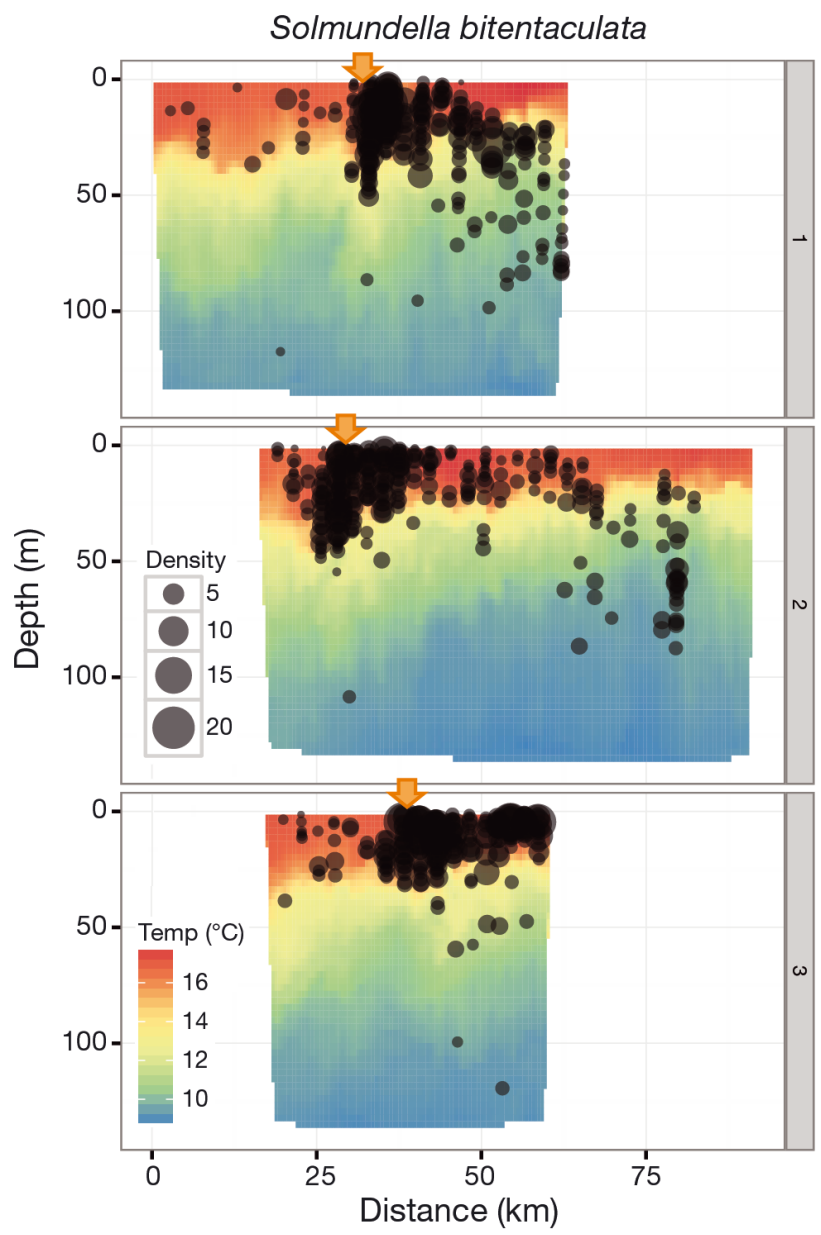

Fig. 7. Density of Solmundella bitentaculata plotted on interpolated temperature. Orange arrows: location of front. Size of bubble indicates concentration of organisms found in a $1 \mathrm{~m}$ depth bin. Distance (in $\mathrm{km}$ ) is measured along each transect. Panel rows in each figure indicate transect (top: Transect 1; middle: Transect 2; bottom: Transect 3) phore and 1 ctenophore), were plotted on top of their most influential variable(s) (Figs. 7-12). S. bitentaculata was found mostly in shallow waters $>15^{\circ} \mathrm{C}$, though some were found deeper in the water column on the east side of the front in Transects 1 and 2 (Fig. 7). Pegantha sp. were found in waters $>16^{\circ} \mathrm{C}$, but mostly on the west side of the transects where fluorometry was $<0.2 \mathrm{~V}$ (Fig. 8). Though Sphaeronectes sp. were found throughout the water column, the highest concentrations were found in waters 10 to $15^{\circ} \mathrm{C}$ and DO 3 to $4.5 \mathrm{ml} \mathrm{l}^{-1}$ (Fig. 9). O. maculata was found deeper, generally where DO was $<3.5 \mathrm{ml} \mathrm{l}^{-1}$ (Fig. 10). The dominant hydromedusa in this study, $S$. rhodoloma, was found in highest concentrations in temperatures ca. $17^{\circ} \mathrm{C}$ and at the front (Fig. 11; see also McClatchie et al. 2012). Highest concentrations of doliolids, which are also known prey of $S$. rhodoloma, were found where fluorometry was $>0.25 \mathrm{~V}$, particularly around $0.3 \mathrm{~V}$ (Fig. 12).

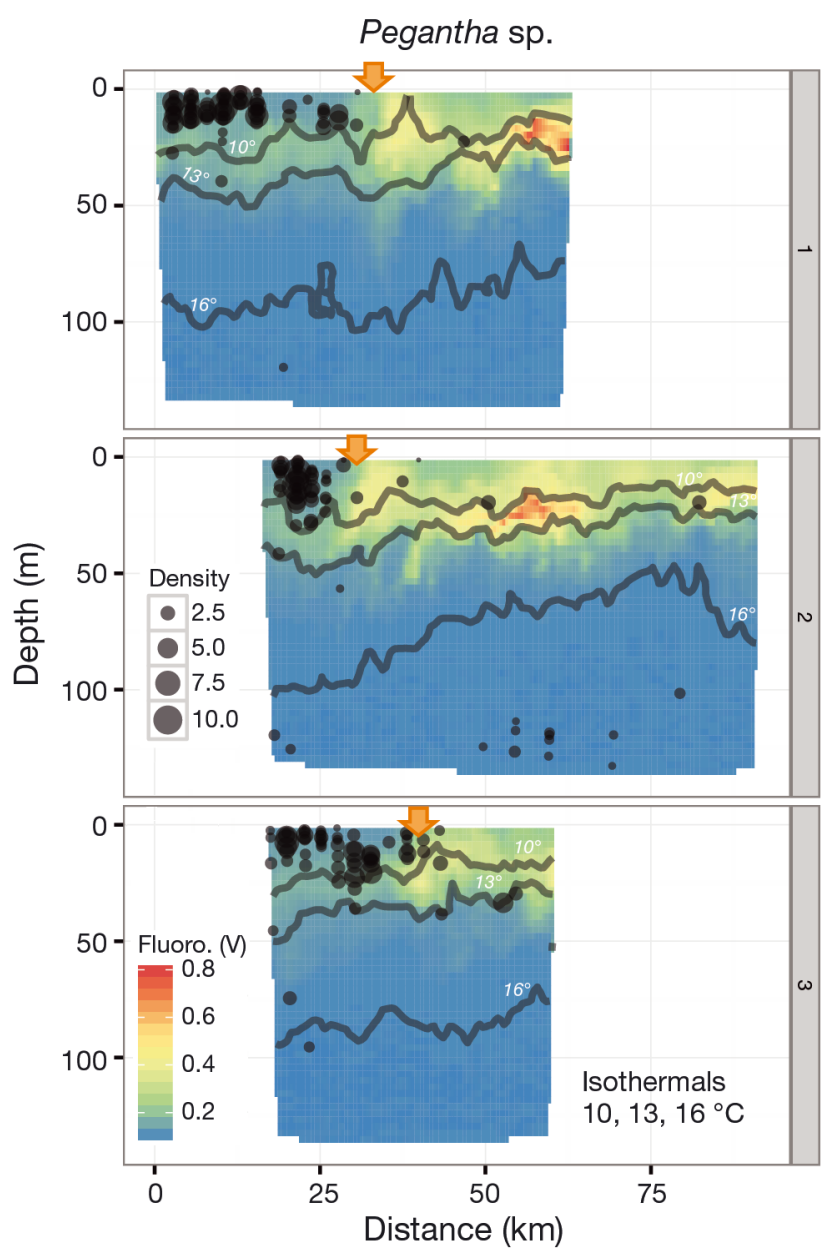

Fig. 8. Density of Pegantha sp. plotted on interpolated fluorometry with contours of 10,13 , and $16^{\circ} \mathrm{C}$ isothermals. See Fig. 7 for further details 


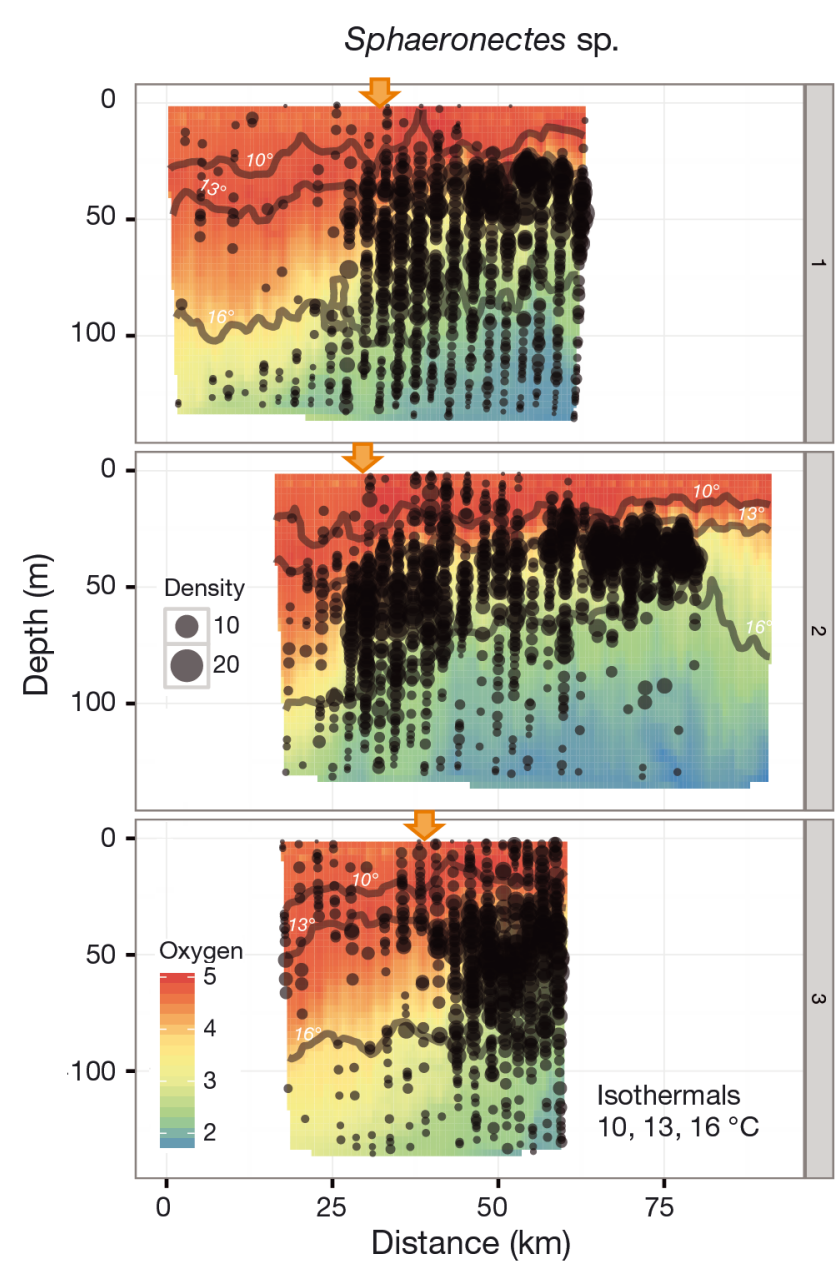

Fig. 9. Density of Sphaeronectes sp. plotted on interpolated oxygen with 10,13 , and $16^{\circ} \mathrm{C}$ isothermals. See Fig. 7 for further details

\section{DISCUSSION}

We present, for the first time, the fine-scale distribution of a community of small gelatinous zooplankton $(<1 \mathrm{~mm}$ bell diameter medusae to $20+\mathrm{cm}$ long siphonophores) and their associated environment across a mesoscale oceanic front. Mesoscale fronts are biologically important because of their frequent occurrence in coastal zones (Kahru et al. 2012), and potential to aggregate both predators and prey (Bakun 2006). We quantified 46 gelatinous zooplankton taxa, and as expected, the abundance distribution by taxa was highly skewed, with the top 5 species representing a disproportionate amount of the total community. Coefficient of variation (SD/mean) values were highest for the hydromedusae, indicating that they were the most patchily distributed. Previous studies have described gelatinous zooplankton communities using net sampling systems that inte-

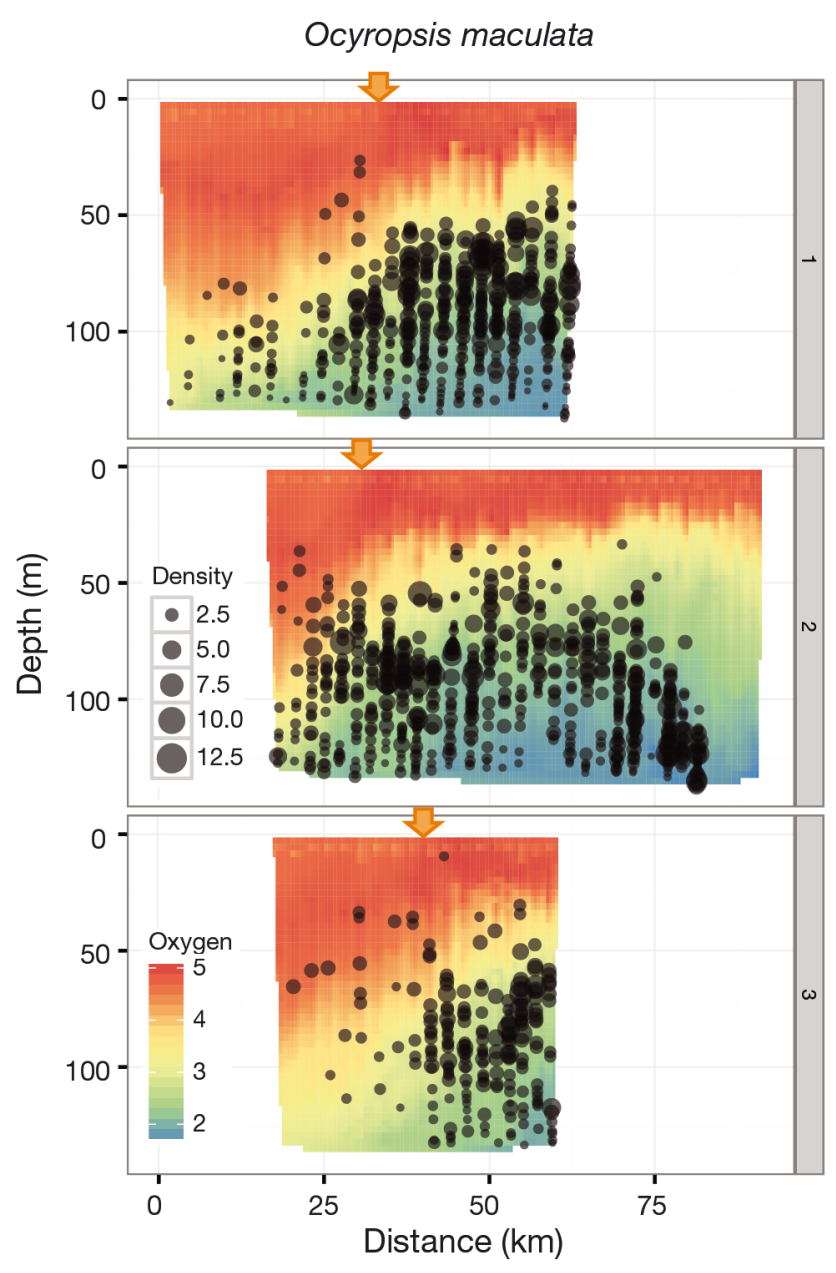

Fig. 10. Density of Ocyropsis maculata plotted on interpolated oxygen. See Fig. 7 for further details

grate over 100s of $\mathrm{m}$ in the horizontal and at least $10 \mathrm{~s}$ of $\mathrm{m}$ of depth (e.g. Pagès et al. 2001, Pavez et al. 2010). Our results provide further support for the diversity and high abundance of small gelatinous zooplankton, which are likely to be major players within the planktonic environment. This examination of community composition and potential interactions has led to a set of possible hypotheses for how fronts structure communities of mid-trophic level organisms.

\section{Physical processes structuring populations and frontal dynamics}

In this study, BRTs, which allowed us to assess the relative importance of a suite of environmental variables in structuring populations, revealed temperature and depth as the most important factors structur- 


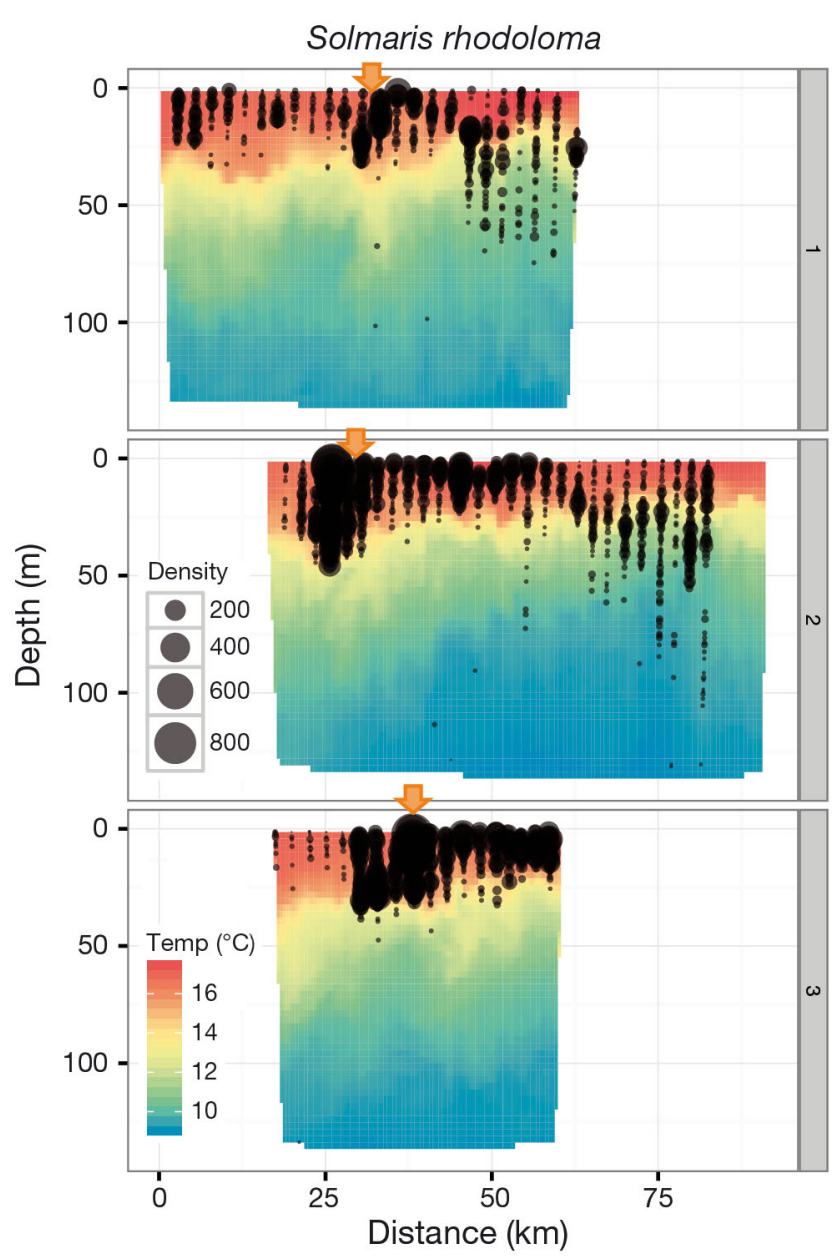

Fig. 11. Solmaris rhodoloma plotted on interpolated temperature. See Fig. 7 for further details

ing gelatinous zooplankton distributions. This is largely due to the numerical dominance of hydromedusae (most influenced by temperature) and appendicularians (most influenced by depth). The positive physiological effect of increased temperatures has been shown to increase respiration and growth rates, and shorten developmental times in hydromedusae (Larson 1987, Matsakis 1993, Møller \& Riisgård 2007, Ma \& Purcell 2005). Many field studies have identified the combined effects of temperature and salinity in driving populations, with higher abundances typically occurring in warm, salty water (Purcell 2005). Thus, it is sometimes difficult to separate the 2 factors, though Purcell (2005) states that temperature has 'the most obvious effects' on medusae abundance and production. It is unknown why changing temperatures would have a greater effect on hydromedusae versus ctenophores and siphonophores, and should be a subject for further investigation.

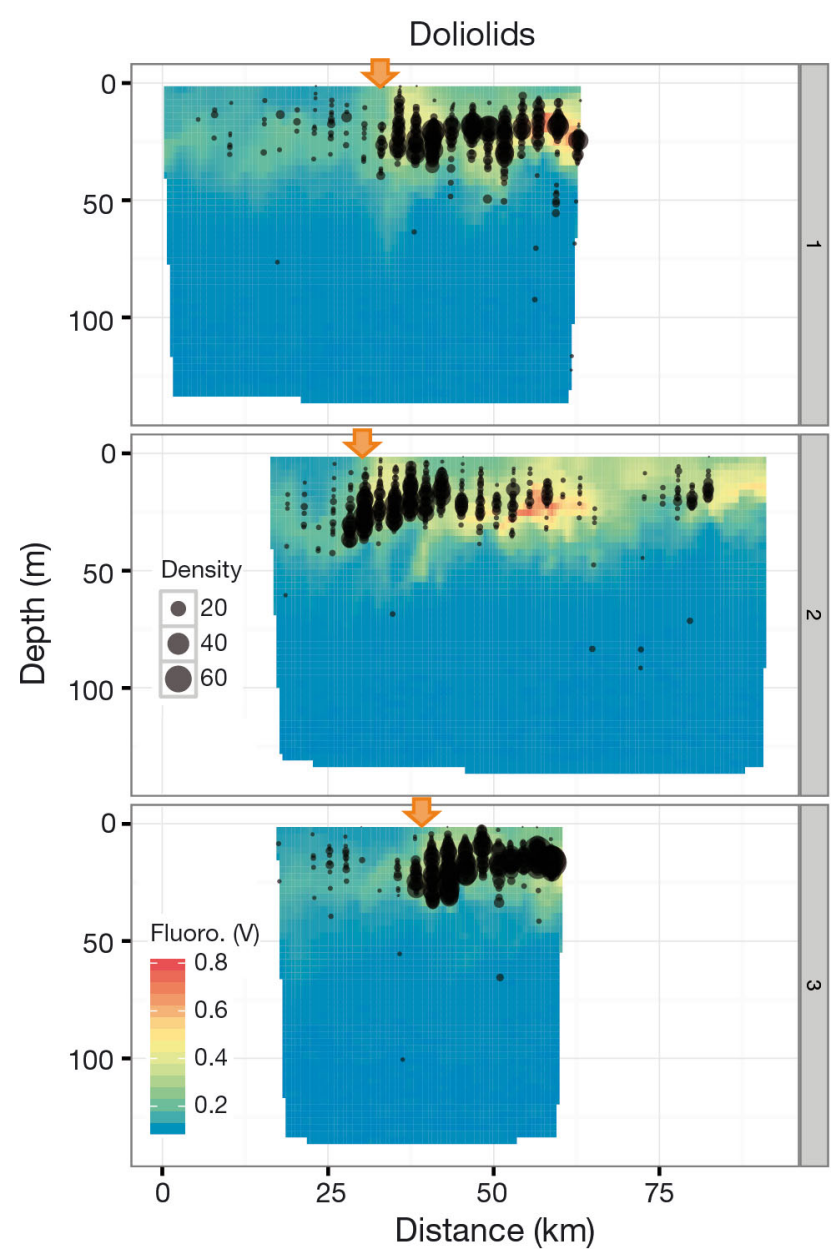

Fig. 12. Doliolids plotted on interpolated fluorometry. See Fig. 7 for further details

What is surprising about the BRT results is not the high influence of temperature and depth in structuring populations, but the low influence of the front and salinity variables, particularly given the strong salinity-driven front in this sampling region. The front contributed $>10 \%$ in only 3 organisms (all hydromedusae), even though they all had moderate to high FAF values. Salinity was also not as influential as we would have expected, with $\leq 20 \%$ contribution in all models except one. The current understanding for how convergent fronts structure biological communities consists of (1) the direct growth and passive advection of primary producers to variations in light and nutrients at the convergence zone, and (2) the accumulation of motile phytoplankton and primary consumers through buoyancy regulation and vertical movements, leading to (3) the active aggregation of predators using sensory cues to hone in on the accumulations of pri- 
mary consumers (Okubo 1978, Owen 1981, Olson \& Backus 1985, Franks 1992, Olson 2002, Bakun 2006, Landry et al. 2012). However, this scenario fails to address the myriad intermediate trophic levels whose behaviors may be altered by the presence of a top predator, or organisms whose distribution might be primarily regulated by other water column characteristics than just the productivity and convergent flow at the front.

Given the primary role of temperature and depth for the majority of surface dwelling organisms, the small role of salinity and the front overall, and the low level of aggregation in species at the front, we propose some possible hypotheses for the observed data:

(1) The convergence zone(s) at fronts is only important for organisms directly in the path of the convergent flow. All other organisms are structured by water mass effects (i.e. some organisms are present in one water mass and not the other). ('Physical structuring effect')

(2) Fronts function as a proximate structuring factor for organisms, with ultimate controlling factors being those that exert a physiological or biological constraint on the organism (e.g. temperature, predation). This is an extension of hypothesis 1, but with a behavioral component. ('Hierarchical structuring effect')

(3) Frontal zones are initially structured by bottomup effects (current understanding), but over time, become dominated by top-down effects through succession. The dominant processes change through the course of frontal development. ('Temporal succession effect')

The physical structuring hypothesis (Hyp. 1) focuses on water mass differences driving compositional differences, and attributes observed differences in community structure at the frontal gradient to physical factors alone. The interaction between depth and the convergent front results in its influence being evident only at certain depths and not at others. However, aggregation was observed in 6 shallow taxa, but not in others present in similar depths, which suggests that there are processes occurring at shallow depths other than convergence alone, such as predation or predator avoidance. Though past studies have attributed different assemblages of zooplankton to water mass differences (e.g. Pagès et al. 2001, Palma \& Silva 2006) and frontal boundaries (Pavez et al. 2010), many were conducted on scales too coarse (sometimes integrating 50 to $100 \mathrm{~m}$ ) to tease out predation effects. Since many plankton patches are $<5 \mathrm{~m}$ in vertical thick- ness (Benoit-Bird et al. 2013b), integrating even $20 \mathrm{~m}$ in the vertical would mask trophic interactions. One possible way of testing this hypothesis is to observe plankton community structure at fronts in the absence of top predators, which would likely occur at the beginning stages of frontal development. Furthermore, it would be important to obtain fine-scale current velocities. Coupled with organism depth and orientation, which is possible to measure with ISIIS (Greer et al. 2013), the relative influence of convergent flow on organisms by depth could be modeled.

The hierarchical structuring hypothesis (Hyp. 2) states that predation, predator avoidance, or physiological constraints are ultimate drivers for population distributions, while the front is a proximate, regulating factor. In the present study, large Solmaris rhodoloma, which comprised $24 \%$ of the hydromedusae and was aggregated in the front in concentrations exceeding 800 ind. $\mathrm{m}^{-3}$, was the dominant predator. S. rhodoloma are obligate predators on other gelatinous zooplankton in a range of sizes, such as doliolids and possibly appendicularians and siphonophores (Purcell \& Mills 1988, Larson et al. 1989, Raskoff 2002). Their aggregation in the top $50 \mathrm{~m}$ at the front could have cascading topdown effects on their prey. However, in deeper waters, many organisms may be structured by other water mass effects, which is evident in some of the BRT results. For example, lobate ctenophores such as Ocyropsis maculata appear primarily influenced by DO levels (48\% in BRT model), with highest concentrations occurring between 2 and $3 \mathrm{ml} \mathrm{l}^{-1} \mathrm{DO}$, suggesting that these ctenophores are primarily attracted to an intermediate DO level. This is consistent with some experimental work showing that lobate ctenophores have an affinity for low DO environments, which do not affect their feeding ability (Kolesar 2006, Kolesar et al. 2010). Proximate vs. ultimate factors also have been used to explain zooplankton diel vertical migrations (Hays 2003, Cohen \& Forward 2009). Examining the effects of fronts with different characteristics (e.g. temperature, density, or chl a driven fronts) on zooplankton communities, particularly gelatinous zooplankton communities, would help determine which factors are regulating (proximate) and which are controlling (ultimate).

The final possible explanation (Hyp. 3) is that the community structure observed in this study was originally formed according to bottom-up effects (Bakun 1996, Olson 2002), but became dominated by top-down effects as the predator 
aggregation became established. Our observation may be of a frontal community post-predator aggregation. Recent studies of end-to-end pelagic food webs suggest that bottom-up effects may be primary in regulating spatial aggregations of predators (Benoit-Bird \& McManus 2012, Benoit-Bird et al. 2013a). This is consistent with the current understanding of how fronts structure biological communities. Indeed, a recent SCB frontal study conducted in October 2008 found elevated concentrations of zooplankton (all non-gelatinous, except the appendicularians and chaetognaths) at a mesoscale front (Ohman et al. 2012). However, in our study, organisms were generally not aggregated at the front, except the large $S$. rhodoloma and a few other mildly to moderately aggregating hydromedusae and doliolids. Additionally, the chl a fluorescence maximum was located 20 to $30 \mathrm{~km}$ inshore (east) of the front in every transect. Thus, it is possible that after the development of the front, there was a succession of dominant organisms in progressively higher trophic levels (like a spring bloom; cf. Porter 1977, Muller et al. 1991, Lochte et al. 1993), culminating in the 'bloom' of $S$. rhodoloma. This jellyfish bloom could have then consumed or driven away other gelatinous zooplankton (their prey) at the frontal discontinuity (a top-down effect), which could explain why there are so few organisms aggregating at the front. With respect to the BRT models, it is possible that the association between $S$. rhodoloma and the front was greater during the initial development of the front, but its influence decreased as the aggregation became established and the population structured by other factors. Since this is a snapshot study, it is not possible to determine at what point during the frontal development and population succession sampling occurred. This highlights the need for more comprehensive studies of mesoscale fronts, particularly those that track the frontal community structure at multiple time points.

\section{Community composition and assemblage analyses}

Aside from a few historical reports (Torrey 1904, 1909, Ritter 1905, Alvariño 1980, Alvariño \& Kimbrell 1987), there have been no recent studies on the gelatinous zooplankton community as a whole, spanning the major functional groups (hydromedusae, siphonophores, ctenophores, and pelagic tunicates) in the California Current. However, there seems to be a general coherence between the spe- cies we found and other reports from the region (cf. Mills \& Haddock 2007, Mills et al. 2007, Mills $\&$ Rees 2007). In fact, nearly all of the taxa we reported in our study, with the exception of the ctenophores, were documented in Alvariño (1980). The only other comprehensive study on ctenophore distribution and assemblages (that we know of) is from Harbison et al. (1978), so our description of the ctenophore community distribution, particularly for lesser described species such as $O$. maculata and Thalassocalyce inconstans, is new for this region.

The species imaged in this study were grouped into 4 assemblages using results from $\mathrm{CA}$, but when combined with correlation analysis and BRT modeling, there were some unexpected divergences within groups and commonalities between groups, which suggest that these assemblages are dynamic. Though negative correlations were observed between assemblage A and the others, similar negative correlations between assemblages B through D were largely absent. Also, assemblage $\mathrm{D}$ and the 2 outliers were slightly positively correlated, instead of being more separated as the clustering might suggest. Correlation analysis uses abundance/concentration data instead of in CA, where the chi-squared distance essentially reflects only presence-absence data in all but the most abundant taxa. Thus, correlation analyses arrived at slightly different results and instead, suggested support for 3 assemblages.

In contrast, the BRT results suggested that there were differences in processes within assemblages. This is highlighted in 2 cases. (1) S. rhodoloma was highly correlated with its known doliolid prey as well as some suspected siphonophore prey (Larson et al. 1989, Raskoff 2002, McClatchie et al. 2012), yet the physical variables that most associated with doliolid and shallow siphonophore populations were different from those most associated with S. rhodoloma populations. Most likely, prey populations (doliolids and small siphonophores) are being consumed, thus effectively occupying a slightly different environmental niche than their predators. Indeed, BRT results for doliolids and the siphonophore Muggiaea atlantica were nearly identical. (2) Two siphonophores, M. atlantica and Sphaeronectes sp., were positively correlated and grouped in the same assemblage, yet the depths of their peak abundances were offset from one another and they showed different environmental influences. These 2 calycorphoans are of a similar shape, size, and feeding strategy, and presumably 
would be feeding on the same prey field (Mackie et al. 1987). While there may be species-specific physiology that would render one taxa more sensitive to temperature or DO, an alternative scenario is that one siphonophore competitively excluded the other, which has resulted in the apparent resource partitioning. This explanation was also proposed by Buecher \& Gibbons (1999) in a distribution study on pelagic cnidarians in the Mediterranean. These examples of community interactions extend the concept of an assemblage beyond merely species presence-absence co-occurrences, which is often used in isolation to describe assemblages in gelatinous zooplankton, larval fish, and other zooplankton (Pagès et al. 2001, ThibaultBotha et al. 2004, Richardson et al. 2010). The processes captured in these analyses (co-occurrence, correlation between abundances, and environmental drivers) each explain different components of species distributions and assemblage characteristics, and are complementary. Assemblages are likely dynamic in non-structured planktonic habitats, and they may reflect some niche separation between plankton taxonomic groups and species.

\section{Using ISIIS to assess gelatinous zooplankton abundance}

It is difficult to use traditional sampling techniques to accurately quantify small gelatinous zooplankton, as they are easily broken apart by nets. Remsen et al. (2004) suggested that nets underestimate pelagic tunicates by over 3 times and cnidarians/ctenophores by 12 times. Even though a formal comparison of gelatinous zooplankton abundances as measured by ISIIS vs. other techniques is not possible in this case, a few broad-stroke comparisons suggest that ISIIS is at least as efficient for estimating small gelatinous zooplankton abundances as net and ROV systems, is able to quantify fine-scale hotspots of high plankton densities, and may be imaging an order of magnitude more small cnidarians than nets typically capture.

While not strictly equal, comparisons with other studies in coastal regions, including California Current and other eastern boundary current sites, reveal similarities in a few taxa but differences for many others. For common siphonophores, $3 \mathrm{yr}$ of ROV sampling in Monterey Bay revealed maximum concentrations of Nanomia bijuga and diphyids to be 0.7 and 0.033 ind. $\mathrm{m}^{-3}$, respectively (Robison et al. 1998, Silguero \& Robison 2000). In comparison, our peak concentrations of $N$. bijuga and diphyid siphonophores were 23 and 9.7 ind. $\mathrm{m}^{-3}$, respectively, which is 33 and 300 times greater than previously reported. In other upwelling systems, a similar order of magnitude difference was also observed for small siphonophores and a common hydromedusa (Pagès et al. 2001, Palma \& Silva 2006, Pavez et al. 2010). However, Raskoff (2001) found blooms of $S$. rhodoloma in similar densities as our study, though we were able to localize high density hotspots within the larger aggregation, with concentrations $>1000$ ind. $\mathrm{m}^{-3}$ (McClatchie et al. 2012). Future work should include systematic comparisons between ISIIS and other sampling systems for estimating gelatinous zooplankton concentrations.

\section{Species-specific behavior}

We also observed some taxa-specific behaviors that are worth briefly noting. In 2 sampling transects, the distribution of Liriope tetraphylla, S. rhodoloma and Solmundella bitentaculata shifted from mid-depths in the afternoon to the surface in the evening, which suggests that these taxa are vertically migrating to the surface at dusk. The most pronounced pattern was observed in L. tetraphylla (Fig. S4 in the Supplement at www.int-res.com/articles/suppl/m510p129_ supp.pdf); organisms were found deeper on the east side of Transects 1 and 2, where the sampling started at $17: 00$ and $16: 35 \mathrm{~h}$, respectively, and continued through the night. Average depths of L. tetraphylla in Transects 1 to 2 decreased $45 \mathrm{~m}$ in $\sim 2 \mathrm{~h}$, such that during the middle of the transect $(\sim 19: 30 \mathrm{~h})$, organisms were within $15 \mathrm{~m}$ of the surface. Note that this change in depth was not observed in Transect 3 because sampling commenced $2 \mathrm{~h}$ later $(21: 00 \mathrm{~h})$. This behavior is consistent with previous reports on L. tetraphylla (Moreira 1973). S. bitentaculata and S. rhodoloma have not previously been shown to vertically migrate, though their relative, Solmissus albescens, can migrate hundreds of meters daily (Mills \& Goy 1988). However, since this study was not designed to investigate vertical migrations, these observations should be further tested in a more targeted study.

The distributions of unidentified larval lobates and O. maculata were in close proximity (but nonoverlapping) with one another, with larval lobates occurring higher in the water column. The relative abundance and concentrations of both are com- 
parable, and a series of life stages are shown in Fig. 3ah-ak, with pictures consistent with that of reported development cycles of Ocyropsis crystallina (Chiu 1963). If the larval lobates are indeed young life stages of $O$. maculata, then this would be the first documentation of ontogenetic vertical migration in ctenophores.

\section{CONCLUSIONS}

We document a high density community of small cnidarians, ctenophores, and pelagic tunicates around a mesoscale front in the Southern California Bight. One extension of our work is to quantify the contribution of small gelatinous zooplankton and pelagic tunicates to carbon cycling in the pelagic oceans. Gelatinous zooplankton have extremely high turnover rates, with appendicularians able to turn over 3 times their body mass daily in house production (Sato et al. 2001). Furthermore, growth rates in jellyfish, after standardization based on carbon content, are 2 times greater than that of pelagic vertebrates (Pitt et al. 2013). In combination with the high densities we documented, this suggests that small gelatinous zooplankton may have a small but significant impact on global carbon cycling. Further investigation on the role of small gelatinous zooplankton in carbon and other nutrient cycling is warranted.

Our description of the fine-scale distribution and physical environment of nearly 50 gelatinous zooplankton taxa allowed us to precisely model the effects of physical variables on species distribution and density. Our results highlight the gaps in our knowledge on how fronts structure planktonic communities, and we propose several hypotheses for further investigation. However, we also fully acknowledge the major limitation of our study in its temporal scale: this is a snapshot of a front over $3 \mathrm{~d}$. Further study needs to be done to investigate the seasonal and annual cycles of gelatinous zooplankton production at fronts and in the California Current system. Furthermore, as mesoscale fronts are incredibly prevalent over a wide band along the California coast, and have already shown multi-decadal increasing trends (Kahru et al. 2012), it is important to understand the influence of different types of fronts (chl $a$, temperature, and salinity fronts) on plankton communities, to describe baseline conditions, and also to predict shifts in community structure with changing ocean conditions.
Acknowledgements. We thank Phil Pugh, Steve Haddock, Dhugal Lindsay, Bill Browne and Casey Dunn for contributing their taxonomic expertise in identifying organisms. Jenna Binstein, Michelle Giorgilli and Allison LaChanse helped with image analysis. Su Sponaugle and Rob Condon contributed helpful discussions and review of earlier drafts. We thank Shin-ichi Uye and 3 anonymous reviewers, whose comments helped improve the manuscript. We thank the Captain and crew of the R/V 'Bell M. Shimada'. Partial funding for this study comes from the NOAA Fisheries Service. J.Y.L. was supported by University of Miami's Maytag Fellowship and a NSF Graduate Research Fellowship.

\section{LITERATURE CITED}

Akima H, Gebhardt A, Petzoldt T, Maechler M (2013) Akima: interpolation of irregularly spaced data. R package version 0.5-10, http://CRAN.R-project.org/package= akima

Alvariño A (1980) The relation between the distribution of zooplankton predators and anchovy larvae. CCOFI Rep 21:150-160

Alvariño A, Kimbrell CA (1987) Abundance of zooplankton species in California coastal waters during April 1981, February 1982 and March 1985. NOAA Technical Memorandum NMFS SWFC 74, La Jolla, CA

Angel MV (1989) Vertical profiles of pelagic communities in the vicinity of the Azores Front and their implications to deep ocean ecology. Prog Oceanogr 22:1-46

Backus RH, Craddock JE, Haedrich RL, Shores DL (1969) Mesopelagic fishes and thermal fronts in western Sargasso Sea. Mar Biol 3:87-106

Bakun A (1996) Patterns in the ocean: ocean processes and marine population dynamics, Vol. California Sea Grant College System, National Oceanic and Atmospheric Administration, in cooperation with Centro de Investigaciones Biológicas de Noroeste, La Paz, Mexico

Bakun A (2006) Fronts and eddies as key structures in the habitat of marine fish larvae: opportunity, adaptive response and competitive advantage. Sci Mar 70:105-122

> Benoit-Bird KJ, McManus MA (2012) Bottom-up regulation of a pelagic community through spatial aggregations. Biol Lett 8:813-816

> Benoit-Bird KJ, Battaile BC, Heppell SA, Hoover B and others (2013a) Prey patch patterns predict habitat use by top marine predators with diverse foraging strategies. PLoS ONE 8:e53348

Benoit-Bird KJ, Shroyer EL, McManus MA (2013b) A critical scale in plankton aggregations across coastal ecosystems. Geophys Res Lett 40:3968-3974

> Buecher E, Gibbons MJ (1999) Temporal persistence in the vertical structure of the assemblage of planktonic medusae in the NW Mediterranean Sea. Mar Ecol Prog Ser 189:105-115

> Castelao RM, Mavor TP, Barth JA, Breaker LC (2006) Sea surface temperature fronts in the California Current System from geostationary satellite observations. J Geophys Res 111:C09026, doi:10.1029/2006JC003541

Chiu SY (1963) The metamorphosis of the ctenophore Ocyropsis crystallina from Amoy. Acta Zool Sin 15:10-16 
Cohen JH, Forward RB (2009) Zooplankton diel vertical migration - a review of proximate control. In: Gibson RN, Atkinson RJA, Gordon JDM (eds) Oceanography and marine biology: an annual review, vol 47. CRC Press-Taylor \& Francis Group, Boca Raton, FL, p 77-109

Cowen RK, Guigand CM (2008) In Situ Ichthyoplankton Imaging System (ISIIS): system design and preliminary results. Limnol Oceanogr Methods 6:126-132

Cowen RK, Greer AT, Guigand CM, Hare JA, Richardson DE, Walsh HJ (2013) Evaluation of the In Situ Ichthyoplankton Imaging System (ISIIS): comparison with the traditional (bongo net) sampler. Fish Bull 111:1-12

Elith J, Leathwick JR, Hastie T (2008) A working guide to boosted regression trees. J Anim Ecol 77:802-813

Franks PJS (1992) Sink or swim: accumulation of biomass at fronts. Mar Ecol Prog Ser 82:1-12

> Friedman JH (2001) Greedy function approximation: a gradient boosting machine. Ann Stat 29:1189-1232

> Graham WM, Pagès F, Hamner WM (2001) A physical context for gelatinous zooplankton aggregations: a review. Hydrobiologia 451:199-212

Graham WM, Martin DL, Martin JC (2003) In situ quantification and analysis of large jellyfish using a novel video profiler. Mar Ecol Prog Ser 254:129-140

Greer AT, Cowen RK, Guigand CM, McManus MA, Sevadjian JC, Timmerman AHV (2013) Relationships between phytoplankton thin layers and the fine-scale vertical distributions of two trophic levels of zooplankton. J Plankton Res 35:939-956

Haddock SHD (2004) A golden age of gelata: past and future research on planktonic ctenophores and cnidarians. Hydrobiologia 530:549-556

> Hamner WM, Madin LP, Alldredge AL, Gilmer RW, Hamner PP (1975) Underwater observations of gelatinous zooplankton: sampling problems, feeding biology, and behavior. Limnol Oceanogr 20:907-917

> Harbison GR, Madin LP, Swanberg NR (1978) On the natural history and distribution of oceanic ctenophores. Deep-Sea Res 25:233-256

> Hays GC (2003) A review of the adaptive significance and ecosystem consequences of zooplankton diel vertical migrations. Hydrobiologia 503:163-170

Kahru M, Di Lorenzo E, Manzano-Sarabia M, Mitchell BG (2012) Spatial and temporal statistics of sea surface temperature and chlorophyll fronts in the California Current. J Plankton Res 34:749-760

Kolesar SE (2006) The effects of low dissolved oxygen on predation interactions between Mnemiopsis leidyi ctenophores and larval fish in the Chesapeake Bay ecosystem. PhD thesis, University of Maryland, College Park, MD

> Kolesar SE, Breitburg DL, Purcell JE, Decker MB (2010) Effects of hypoxia on Mnemiopsis leidyi, ichthyoplankton and copepods: clearance rates and vertical habitat overlap. Mar Ecol Prog Ser 411:173-188

Koubbi P (1993) Influence of the frontal zones on ichthyoplankton and mesopelagic fish assemblages in the Crozet Basin (Indian sector of the Southern Ocean). Polar Biol 13:557-564

> Landry MR, Ohman MD, Goericke R, Stukel MR, Barbeau KA, Bundy R, Kahru M (2012) Pelagic community responses to a deep-water front in the California Current ecosystem: overview of the A-front study. J Plankton Res 34:739-748

Lara-Lopez AL, Davison P, Koslow JA (2012) Abundance and community composition of micronekton across a front off Southern California. J Plankton Res 34:828-848

Larson RJ (1987) Respiration and carbon turnover rates of medusae from the NE Pacific. Comp Biochem Physiol A $87: 93-100$

Larson RJ, Mills CE, Harbison GR (1989) In situ foraging and feeding behaviour of narcomedusae (Cnidaria: Hydrozoa). J Mar Biol Assoc UK 69:785-794

Lochte K, Ducklow HW, Fasham MJR, Stienen C (1993) Plankton succession and carbon cycling at $47^{\circ} \mathrm{N} 20^{\circ} \mathrm{W}$ during the JGOFS North Atlantic bloom experiment. Deep-Sea Res II 40:91-114

> Ma XP, Purcell JE (2005) Temperature, salinity, and prey effects on polyp versus medusa bud production by the invasive hydrozoan Moerisia lyonsi. Mar Biol 147: $225-234$

> Mackie GO, Mills CE (1983) Use of the PISCES IV submersible for zooplankton studies in coastal waters of British Columbia. Can J Fish Aquat Sci 40:763-776

> Mackie GO, Pugh PR, Purcell JE (1987) Siphonophore biology. Adv Mar Biol 24:97-262

Madin LP (1988) Feeding behavior of tentaculate predators: in situ observations and a conceptual model. Bull Mar Sci 43:413-429

Madin LP, Horgan E, Gallager SM, Eaton J, Girard A (2006) LAPIS: a new imaging tool for macrozooplantkon. In: Proc Oceans 2006 - Boston. IEEE/MTS, Boston, MA

Matsakis S (1993) Growth of Clytia spp. hydromedusae (Cnidaria, Thecata): effects of temperature and food availability. J Exp Mar Biol Ecol 171:107-118

McClatchie S, Cowen R, Nieto K, Greer A and others (2012) Resolution of fine biological structure including small narcomedusae across a front in the Southern California Bight. J Geophys Res 117:C04020, doi:10.1029/2011JC 007565

Mills CE (1984) Density is altered in hydromedusae and ctenophores in response to changes in salinity. Biol Bull 166:206-215

Mills CE, Goy J (1988) In situ observations of the behavior of mesopelagic Solmissus narcomedusae (Cnidaria, Hydrozoa). Bull Mar Sci 43:739-751

Mills CE, Haddock SHD (2007) Key to the Ctenophora. In: Carlton JT (ed) Light and Smith's manual: intertidal invertebrates from Central California to Oregon. University of California Press, Berkeley, CA, p 189-199

Mills CE, Rees JT (2007) Key to the Hydromedusae. In: Carlton JT (ed) Light and Smith's manual: intertidal invertebrates from Central California to Oregon. University of California Press, Berkeley, CA, p 137-168

Mills CE, Haddock SHD, Dunn CW, Pugh PR (2007) Key to the Siphonophora. In: Carlton JT (ed) Light and Smith's manual: intertidal invertebrates from Central California to Oregon. University of California Press, Berkeley, CA, p 150-166

> Møller LF, Riisgård HU (2007) Respiration in the scyphozoan jellyfish Aurelia aurita and two hydromedusae (Sarsia tubulosa and Aequorea vitrina): effect of size, 
temperature and growth. Mar Ecol Prog Ser 330: 149-154

Moreira GS (1973) On the diurnal vertical migration of hydromedusae off Santos, Brazil. Publ Seto Mar Biol Lab 20:537-566

Muller H, Schone A, Pintocoelho RM, Schweizer A, Weisse $\mathrm{T}$ (1991) Seasonal succession of ciliates in Lake Constance. Microb Ecol 21:119-138

Ohman MD, Powell JR, Picheral M, Jensen DW (2012) Mesozooplankton and particulate matter responses to a deep-water frontal system in the southern California Current System. J Plankton Res 34:815-827

Okubo A (1978) Advection diffusion in the presence of surface convergence. In: Bowman MJ, Esaias WE (eds) Oceanic fronts in coastal processes. Springer, Berlin, p 23-28

Olson DB (2002) Biophysical dynamics of ocean fronts. In: Robinson AR, McCarthy JJ, Rothschild BJ (eds) The Sea, Vol 12. John Wiley \& Sons, New York, NY

Olson DB, Backus RH (1985) The concentrating of organisms at fronts: a cold-water fish and a warm-core gulf stream ring. J Mar Res 43:113-137

> Ortner PB, Hill LC, Edgerton HE (1981) In-situ silhouette photography of Gulf Stream zooplankton. Deep-Sea Res I 28:1569-1576

Owen RW (1981) Fronts and eddies in the sea: mechanisms, interactions and biological effects. In: Longhurst AR (ed) Analysis of marine ecosystems. Academic Press, New York, NY, p 197-233

Pagès F, Gili JM (1991) Effects of large-scale advective processes on gelatinous zooplankton populations in the northern Benguela ecosystem. Mar Ecol Prog Ser 75: 205-215

Pagès F, González HE, Ramón M, Sobarzo M, Gili JM (2001) Gelatinous zooplankton assemblages associated with water masses in the Humboldt Current System, and potential predatory impact by Bassia bassensis (Siphonophora: Calycophorae). Mar Ecol Prog Ser 210: 13-24

> Pakhomov EA, Perissinotto R, Mcquaid CD (1994) Comparative structure of the macrozooplankton micronekton communities of the subtropical and Antarctic polar fronts. Mar Ecol Prog Ser 111:155-169

Palma S, Silva N (2006) Epipelagic siphonophore assemblages associated with water masses along a transect between Chile and Easter Island (eastern South Pacific Ocean). J Plankton Res 28:1143-1151

> Pavez MA, Landaeta MF, Castro LR, Schneider W (2010) Distribution of carnivorous gelatinous zooplankton in the upwelling zone off central Chile (austral spring 2001). J Plankton Res 32:1051-1065

> Pebesma EJ (2004) Multivariable geostatistics in S: the gstat package. Comput Geosci 30:683-691

> Pitt KA, Welsh DT, Condon RH (2009) Influence of jellyfish blooms on carbon, nitrogen and phosphorus cycling and plankton production. Hydrobiologia 616:133-149

Pitt KA, Duarte CM, Lucas CH, Sutherland KR and others (2013) Jellyfish body plans provide allometric advantages beyond low carbon content. PLoS ONE 8:e72683

Porter KG (1977) The plant-animal interface in freshwater ecosystems. Am Sci 65:159-170
Purcell JE (2005) Climate effects on formation of jellyfish and ctenophore blooms: a review. J Mar Biol Assoc UK 85:461-476

Purcell JE (2012) Jellyfish and ctenophore blooms coincide with human proliferations and environmental perturbations. Ann Rev Mar Sci 4:209-235

Purcell JE, Arai MN (2001) Interactions of pelagic cnidarians and ctenophores with fish: a review. Hydrobiologia 451:27-44

Purcell JE, Mills CE (1988) The correlation between nematocyst types and diets in pelagic hydrozoa. In: Hessinger DA, Lenhoff HM (eds) The biology of nematocysts. Academic Press, Orlando, FL, p 463-485

Raskoff KA (2001) The ecology of the mesopelagic hydromedusae in Monterey Bay, California. PhD thesis, University of California, Los Angeles, CA

Raskoff KA (2002) Foraging, prey capture, and gut contents of the mesopelagic narcomedusa Solmissus spp. (Cnidaria: Hydrozoa). Mar Biol 141:1099-1107

R Development Core Team (2013) R: a language and environment for statistical computing. Foundation for Statistical Computing, Vienna. http://www.R-project.org

Remsen A, Hopkins TL, Samson S (2004) What you see is not what you catch: a comparison of concurrently collected net, optical plankton counter, and shadowed image particle profiling evaluation recorder data from the northeast Gulf of Mexico. Deep-Sea Res I 51: 129-151

Richardson DE, Llopiz JK, Guigand CM, Cowen RK (2010) Larval assemblages of large and medium-sized pelagic species in the Straits of Florida. Prog Oceanogr 86:8-20

Ridgeway G (2012) Generalized boosted models: a guide to the gbm package. http://gradientboostedmodels. googlecode.com/git/gbm/inst/doc/gbm.pdf

Ridgeway G (2013) Gbm: generalized boosted regression models. R package version 2.1. http://gradientboosted models.googlecode.com/git/gbm/inst/doc/gbm.pdf

Ritter WE (1905) Contributions from the laboratory of the Marine Biological Association of San Diego. III. The pelagic Tunicata of the San Diego region, excepting the Larvacea. Univ Calif Publ Zool 6:51-112

Robison BH, Reisenbichler KR, Sherlock RE, Silguero JMB, Chavez FP (1998) Seasonal abundance of the siphonophore, Nanomia bijuga, in Monterey Bay. Deep-Sea Res II 45:1741-1751

Rudnick DL, Davis RE, Eriksen CC, Fratantoni DM, Perry MJ (2004) Underwater gliders for ocean research. Mar Tech Soc J 38:73-84

Samson S, Hopkins T, Remsen A, Langebrake L, Sutton T, Patten J (2001) A system for high-resolution zooplankton imaging. IEEE J Oceanic Eng 26:671-676

Sato R, Tanaka Y, Ishimaru T (2001) House production by Oikopleura dioica (Tunicata, Appendicularia) under laboratory conditions. J Plankton Res 23:415-423

Silguero JMB, Robison BH (2000) Seasonal abundance and vertical distribution of mesopelagic calycophoran siphonophores in Monterey Bay, CA. J Plankton Res 22: 1139-1153

Thibault-Botha D, Lutjeharms JRE, Gibbons MJ (2004) Siphonophore assemblages along the East coast of 
South Africa; mesoscale distribution and temporal variations. J Plankton Res 26:1115-1128

Todd RE, Rudnick DL, Mazloff MR, Davis RE, Cornuelle BD (2011) Poleward flows in the southern California Current System: glider observations and numerical simulation. J Geophys Res 116:C02026, doi: 10.1029/2010JC006536

Torrey HB (1904) Contributions from the laboratory of the Marine Biological Association of San Diego. II. The Ctenophores of the San Diego region. Univ Calif Publ Zool 6:45-51

Submitted: November 25, 2013; Accepted: June 7, 2014
Torrey HB (1909) Contributions from the laboratory of the Marine Biological Association of San Diego. I. The Leptomedusae of the San Diego region. Univ Calif Publ Zool 6:11-31

Tsechpenakis G, Guigand C, Cowen RK (2007) Image analysis techniques to accompany a new In Situ Ichthyoplankton Imaging System. In: Proc Oceans 2007 - Europe. IEEE, Aberdeen, p 1-6

Tsechpenakis G, Guigand C, Cowen RK (2008) Machine vision-assisted In Situ Ichthyoplankton Imaging System. Sea Technol 49:15-20

Proofs received from author(s): August 26, 2014 